Florida International University FIU Digital Commons

$11-14-2014$

\title{
Exploring the Use of Everglades Agricultural Area Canal Water as Base Medium for the Mass Production of Algae for Biofuels
}

Nina N. De la Rosa

Florida International University, ndela017@fiu.edu

DOI: $10.25148 /$ etd.FI14110769

Follow this and additional works at: https://digitalcommons.fiu.edu/etd

Part of the Other Environmental Sciences Commons

\section{Recommended Citation}

De la Rosa, Nina N., "Exploring the Use of Everglades Agricultural Area Canal Water as Base Medium for the Mass Production of Algae for Biofuels" (2014). FIU Electronic Theses and Dissertations. 1689.

https://digitalcommons.fiu.edu/etd/1689 


\title{
FLORIDA INTERNATIONAL UNIVERSITY \\ Miami, Florida
}

\section{EXPLORING THE USE OF EVERGLADES AGRICULTURAL AREA CANAL WATER AS BASE MEDIUM FOR THE MASS PRODUCTION OF ALGAE FOR BIOFUELS}

\author{
A thesis submitted in partial fulfillment of the \\ requirements for the degree of \\ MASTER OF SCIENCE \\ in \\ ENVIRONMENTAL STUDIES \\ by
}

Nina De la Rosa 2014 
To: Interim Dean Michael R. Heithaus

College of Arts and Sciences

This thesis, written by Nina De la Rosa, and entitled Exploring the Use of Everglades Agricultural Area Canal Water as Base Medium for the Mass Production of Algae for Biofuels, having been approved in respect to style and intellectual content, is referred to you for judgment.

We have read this thesis and recommend that it be approved.

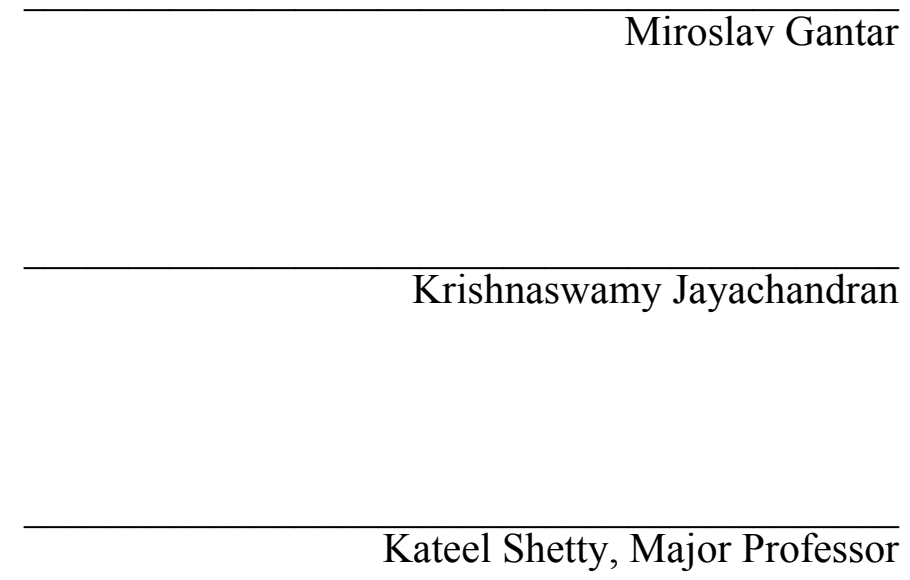

Date of Defense: November 14, 2014

The thesis of Nina De la Rosa is approved.

$\begin{array}{r}\begin{array}{r}\text { Interim Dean Michael R. Heithaus } \\ \text { College of Arts and Sciences }\end{array} \\ \hline \begin{array}{r}\text { Dean Lakshmi N. Reddi } \\ \text { University Graduate School }\end{array}\end{array}$

Florida International University, 2014 


\section{DEDICATION}

I dedicate this thesis to my parents Francesca and Rafael De la Rosa. Their love and support have carried me through this process. To Andrew, whose love and

encouragement keep me strong. And to Lily, Marshall, and Punky, who showed me that life is a better journey with paws by your side. 


\section{ACKNOWLEDGMENTS}

I am deeply indebted to my major advisor Dr. Kateel G. Shetty, for his constant guidance, patience, and motivation throughout my graduate career, without which I could not have accomplished this work. I am extremely grateful to Dr. Krish Jayachandran, whose mentorship has helped me through my research and will continue to be useful throughout my career. In addition, I would like thank him for providing the opportunity of a research assistantship under the Agroecology Program. I also wish to acknowledge the help of Dr. Miroslav Gantar for devoting not only his time and knowledge but also providing me with his valuable critique and suggestions in developing this thesis.

I am tremendously thankful to David Berthold from the Algal Biotechnology Laboratory at Florida International University for his support throughout this entire project. I convey my special thanks to Nikki Onuoha and Barbara Pazos for their assistance with sample collection, and to Beyte Barrios and Jingan Qu for their help with statistical analysis. I would also like Dr. Stewart Reed and Mr. Chris Dunn for their assistance with instrumentation needed for the completion of my work. I would also like to thank Colonel John Mills and his staff at CASA for their assistance with the set-up for part of this project. I also deeply acknowledge Dr. Mahadev Bhat and Mrs. Stephany Alvarez-Ventura for their continued encouragement and assistance throughout my time in the Agroecology Program.

I finally thank the Almighty for blessing me with a wonderful family and friends who have always been a source of strength and inspiration for me. I deeply appreciate all their help and our time together. Funding for this project was provided by USDA-NIFANational Needs Fellows- 2011-38420-20053. 


\section{ABSTRACT OF THE THESIS \\ EXPLORING THE USE OF EVERGLADES AGRICULTURAL AREA CANAL WATER AS BASE MEDIUM FOR THE MASS PORDUCTION OF \\ ALGAE FOR BIOFUELS \\ by}

Nina De la Rosa

Florida International University, 2014

Miami, Florida

Professor Kateel Shetty, Major Professor

Freshwater use is a major concern in the mass production of algae for biofuels. This project examined the use of canal water obtained from the Everglades Agricultural Area as a base medium for the mass production of algae. This water is not suitable for human consumption, and it is currently used for crop irrigation. A variety of canals were found to be suitable for water collection. Comparison of two methods for algal production showed no significant difference in biomass accumulation. It was discovered that synthetic reticulated foam can be used for algal biomass collection and harvest, and there is potential for its application in large-scale operations. Finally, it was determined that high alkaline conditions may help limit contaminants and competing organisms in growing algae cultures. 


\section{TABLE OF CONTENT}

SECTION

PAGE

1. INTRODUCTION ...................................................... 1

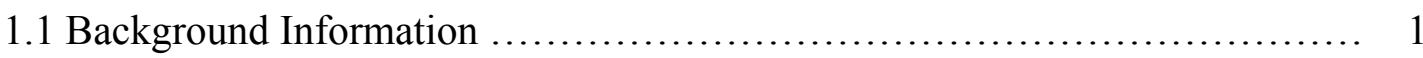

1.2 Statement of Research ................................................ 3

1.3 Hypothesis ............................................................. 3

2. LITERATURE REVIEW .................................................... 5

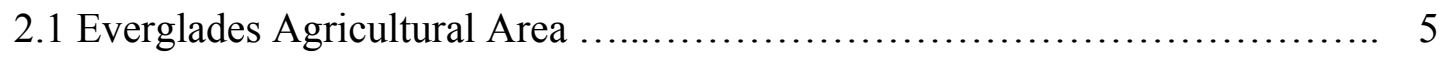

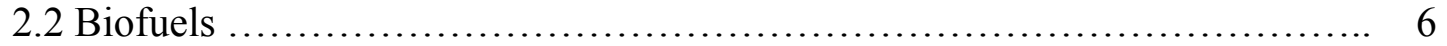

2.2.1 First Generation Biofuels ....................................... 6

2.2.2 Second Generation Biofuels ......................................... 7

2.2.3 Third Generation Biofuels ............................................ 8

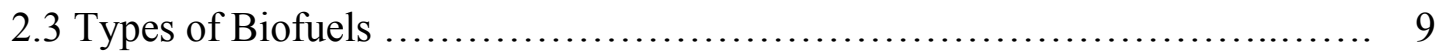

2.3.1 Ethanol ............................................................ 9

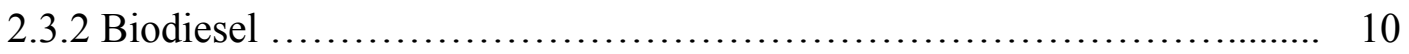

2.3.3 1- Butanol ........................................................... 11

2.3.3.1 ABE Fermentation .......................................... 12

2.4 Use of Algae as Feedstock for Biofuels ................................ 13

2.4.1 Mass Production of Algae ...................................... 15

2.5 Water and Algae Production .......................................... 18

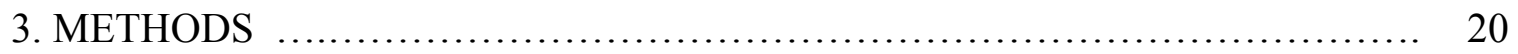

3.1 Assessment of Canal Water Suitability for Algae Growth ................... 20

3.2 Assessment of Different Growth Media .................................... 22

3.2.1 Media Preparation .............................................. 23

3.3 Different Systems for Biomass Growth ................................... 25

3.3.1 Raceway Pond ................................................ 27

3.3.2 Semi-Submerged, Immobilized Algae Cell System ....................... 28

3.3.3 Quantification of Biomass ........................................... 29

3.4 The Use of Reticulated Foam for Algal Biomass Production ................. 30

3.4.1 Quantification of Biomass ............................................. 31

3.5 The Impact of Alkaline $\mathrm{pH}$ on Algal Growth ............................... 31

3.5.1 Experiment Set-up ............................................ 32

3.6 Statistical Analysis ................................................... 33

3.6.1 Canal Water Suitability for Algae Growth .......................... 33

3.6.2 Assessment of Different Growth Media .............................. 33

3.6.3 Biomass Production in a Raceway Pond System and Semi-Submerged, Immobilized Cell System ............................................ 34

3.6.4 The Use of Reticulated Foam for Algal Biomass Production ............. 34

4. RESULTS …................................................................ 35

4.1 Biomass in Canal Water ............................................ 35 
4.2 Biomass in Canal Water Supplemented with Nutrients $\ldots \ldots \ldots \ldots \ldots \ldots \ldots \ldots \ldots . . \ldots$

4.2.1 Total Chlorophyll ............................................... 36

4.2.2 Dry Weight .................................................... 37

4.3 Biomass Production in a Raceway Pond System ......................... 39

4.4 Biomass Production in a Semi-Submerged, Immobilized Cell System ........ 40

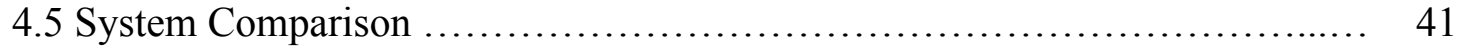

4.6 The Use of Reticulated Foam for Algal Biomass Production ............... 42

4.6.1 Chlorophyll .................................................. 42

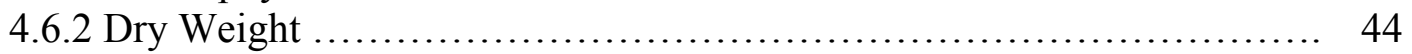

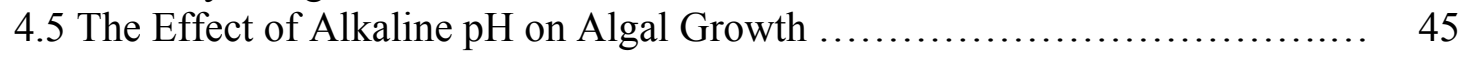

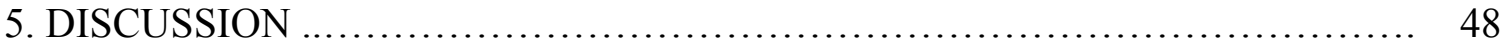

5.1 Assessment of Canal Water Suitability for Algae Growth .................. 48

5.2 Media Comparison ................................................ 49

5.3 Biomass Production in a Raceway Pond System and Semi-Submerged, Immobilized Cell System ............................................ 51

5.4 The Use of Reticulated for Algal Biomass Production ..................... 53

5.5 The Impact of Alkaline $\mathrm{pH}$ on Algae Growth .......................... 54

6. CONCLUSION ................................................... 57

7. RECOMMENDATIONS ................................................ 58

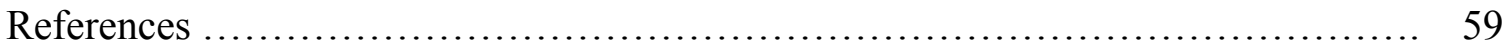




\section{LIST OF TABLES}

TABLE

PAGE

Table 1: Formulas used in the calculation of pigments $\ldots \ldots \ldots \ldots \ldots \ldots \ldots \ldots \ldots \ldots \ldots . \ldots \ldots \ldots \ldots$

Table 2: Chu Medium Recipe ............................................ 23

Table 3: Recipe for DyIII Medium ......................................... 24

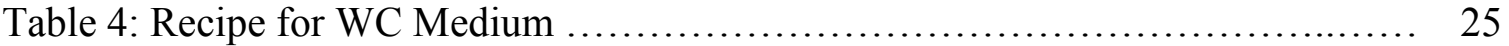

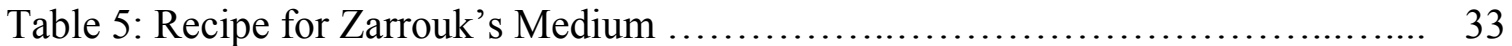




\section{LIST OF FIGURES}

FIGURE

PAGE

Figure 1: Everglades Agricultural Area (South Florida Water Management 6

District)

Figure 2: Schematic Diagram of an Open Pond (Christi, 2007) ................ 16

Figure 3: Schematic Diagram of an Enclosed Photobioreactor (Christi, 2007) ..... 17

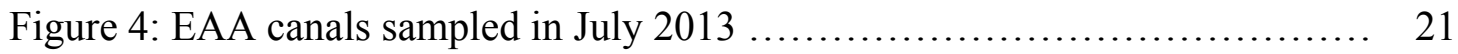

Figure 5: Raceway Pond (RW) and Suspended Rotary System (SRS) Mesocosm

Set-Up. Bins marked with the yellow cross represent those that received a nutrient treatment

Figure 6: Mesocosms set-up at CASA

Figure 7: Mimic Raceway Pond

Figure 8: Semi-Submerged, Rotary System.

Figure 9: Chlorophyll (in $\mu \mathrm{g} \cdot \mathrm{mL}^{-1}$ ) concentrations found in the EAA canals sampled in July 2013. Site LOX was found to be significantly higher than the rest of the canals sampled

Figure 10: Mean Total Chlorophyll (in $\mu \mathrm{g} \cdot \mathrm{mL}^{-1}$ ) Comparison among Sampling Sites per Media. No significant difference was found among media $\left[\mathrm{X}^{2}(2\right.$, $\mathrm{N}=27)=1.91 ; \mathrm{p}=0.39]$ or among sites $\left[\mathrm{X}^{2}(2, \mathrm{~N}=27)=2.77 ; \mathrm{p}=0.25\right]$

Figure 11: Mean Total Biomass Dry Weight (gr/l) Comparison among Sampling Sites. No significant difference was found among the three different media $\left[\mathrm{X}^{2}(2, \mathrm{~N}=27)=0.23 ; \mathrm{p}=0.9\right]$ or among the three sites $\left[\mathrm{X}^{2}(2\right.$, $\mathrm{N}=27)=2.39 ; \mathrm{p}=0.1]$

Figure 12: Mean Total Biomass (gr/l) in Raceway Pond Systems. Significant difference was found between the bins that received the nutrient treatment $(\mathrm{M}=3.77, \mathrm{SD}=1.41)$ and those that $\operatorname{did} \operatorname{not}(\mathrm{M}=0.89, \mathrm{SD}=0.50), \mathrm{t}(8)=2.21$; $\mathrm{p}=0.00$

Figure 13: Mean Total Biomass (gr/l) in Semi-Submerged, Immobilized Cell Systems. Significant difference was found between the bins that received the nutrient treatment $(\mathrm{M}=3.98, \mathrm{SD}=0.78)$ and those that $\operatorname{did} \operatorname{not}(\mathrm{M}=0.79, \mathrm{SD}=$ $0.58), \mathrm{t}(8)=0.99, \mathrm{p}=0.00$ 
Figure 14: Mean total biomass (gr/l) accumulated in two tested systems; raceway ponds and suspended rotary systems and nutrient treatment

Figure 15: Water collected from the mesocosms. Difference in color can be observed between the bins that received nutrient treatment (right) and those that did not (left)

Figure 16: Total mean chlorophyll (ug. $\mathrm{mL}^{-1}$ ) of cultures with and without the foam over the experiment time (45 days).

Figure 17: Difference in Chlorophyll levels (ug. $\mathrm{mL}^{-1}$ ) between the cultures where the foam was added and cultures where the foam was not added. No significant difference was found $\mathrm{t}(18)=1.48, \mathrm{p}>0.05$

Figure 18: Mean Total Biomass (gr/l) Accumulated in Samples With and Without Reticulated Foam. Samples including the foam displayed a significantly higher amount of biomass $\mathrm{t}(18)=2.6, \mathrm{p}=0.018$

Figure 19: Mean Total Chlorophyll (ug. $\mathrm{mL}^{-}$) Displayed in Cultures Grown in Zarrouk's Medium over 35 Days

Figure 20: Algae Consortia Present in Cultures from Site S308 Growing in Zarrouk's Medium at Unmodified $\mathrm{pH}(8.9)$

Figure 21: Algae Present in Cultures from Site S308 Growing in Zarrouk's Medium at $\mathrm{pH} 10$ at 35 Days 


\section{LIST OF ABREVIATIONS}

\begin{tabular}{|c|c|}
\hline GHG & Green House Gases \\
\hline $\mathrm{CO} 2$ & Carbon Dioxide \\
\hline EAA & Everglades Agricultural Area \\
\hline WCA & Water Conservation Area \\
\hline $\mathrm{ABE}$ & Acetone Butanol Ethanol \\
\hline BTU & British Thermal Unit \\
\hline SFWMD & South Florida Water Management District \\
\hline$\mu \mathrm{m}$ & Micron meter \\
\hline $\mathrm{cm}$ & Centimeter \\
\hline $\mathrm{m}$ & Meter \\
\hline M & Molar \\
\hline $\mathrm{nm}$ & Nanometer \\
\hline${ }^{\circ} \mathrm{C}$ & Degree Celsius \\
\hline $\mathrm{m}^{3}$ & Cubic Meters \\
\hline psi & Pounds per Square Inch \\
\hline $\mathrm{mL}$ & Milliliter \\
\hline rpm & Revolutions Per Minute \\
\hline$\mu \mathrm{g} / \mathrm{L}$ & Microgram per Liter \\
\hline $\mathrm{L}$ & Liter \\
\hline $\mathrm{g}$ & Grams \\
\hline $\mathrm{mg}$ & Milligrams \\
\hline
\end{tabular}


Lm Lumens 


\section{INTRODUCTION}

\subsection{Background Information}

The U.S. has a long history of crude oil dependency. In 1870, one percent of the country's yearly energy demand was met by four million barrels of domestically produced oil (Enger and Smith, 2002). The petroleum demand rapidly increased in the 1900 's with the popularization of the automobile, and by 1950, petroleum-based fuels were the most consumed fuels, and their demand surpassed domestic production for the first time (EIA, 2012). In 1950, the energy imports started in the U.S. (EIA, 2012). In 1970, fifty percent of the nation's energy demand was met by oil (Enger and Smith, 2002). Today, that number is far surpassed as petroleum-based fuels continue to be the most popular fuels.

Although the generation of electricity is responsible for the majority of the energy used in the U.S., the transportation sector is a large and important contributor. Utilizing a total of twenty seven quads of energy per year, transportation accounts for twenty eight percent of the total energy consumed (EIA, 2012). For this, petroleum fuels supply ninety three percent of the energy demanded (EIA, 2012). The ample use of private automobiles is largely responsible for demand of liquid fuel. In fact, cars in America consume fifteen percent of the oil produced worldwide, while the rest of the automobiles in the world consume about seven percent (Enger and Smith, 2002).

The extensive use of petroleum fuels for transportation has been the subject of much criticism, notably because this consumption sustains the need of fossil fuel imports, typically originating in politically unstable nations. Moreover, fossil fuel combustion from the transportation sector is currently the largest source of carbon dioxide $\left(\mathrm{CO}_{2}\right)$, a 
primary Greenhouse Gas (GHG) (EIA, 2012). In 1999, the transportation sector's $\mathrm{CO}_{2}$ emissions exceeded those from the industrial sector for the first time, and in 2011, the transportation sector generated thirty four percent of all $\mathrm{CO}_{2}$ emissions from energy consumption in America (EIA, 2012). The rapid diminishing of oil reserves and increasing prices of fossil fuels, combined with increasing concerns of energy security and climate change have led to the research and development of renewable, cleaner energies such as, biomass derived fuels or biofuels (Christi, 1980).

Biofuels are currently the only marketable option for liquid fuel for transportation (Halim, et al., 2011). Presently, commercial biofuels are manufactured exclusively from corn and soybean. However, research on the potential of non-edible crops as feedstock is advancing, making biofuels more competitive. Algal biofuels have sparked a lot of interest, given their photosynthetic efficiency and capability to store high quantity of lipids. Although the manufacturing of biofuels has been expanded to include an extensive list of possible feedstock, all current agriculture-based fuels utilize large quantities of fresh water. Research addressed by the United Nations cited fresh water supply and energy intensification involved in culture collection, drying and lipid extraction for algae to be major concerns for third generation biofuels (Waltz, 2013). As a response to these concerns, several authors have suggested wastewater as growth medium for microalgae (Oswald and Gotaas, 1957; Goldman, 1979; Soedes, 1980; Udoma, et al., 2012; Yuan, et al., 2012; Christenson \& Sims, 2011); however, empirical data are not abundant. My research aims at utilizing agricultural waste water obtained from the canals in the Everglades Agricultural Area (EAA). To date, no research that targets the use of South Florida canal water has been published. Using canal water as a base medium alleviates 
the pressure that biofuels have on clean water supplies, and it may facilitate the mitigation of excess nutrients when appropriate.

\subsection{Statement of Research}

The main goal of my thesis project is to ascertain the viability of utilizing native Florida microalgae and canal water for the production of third generation biofuels. An open-air experimental method was set up to grow algae on FIU's Center for Agroecology and Sustainable Agriculture (CASA) under natural South Florida conditions. More specifically, two growing systems were be tested: a typical raceway pond where suspended algae will circulate and a semi-submerged, rotary surface where algae where attached.

\subsection{Hypothesis}

My research is focused on two hypotheses: (1) Native microalgae can be successfully grown in EAA canal water in controlled systems for the purpose of biomass growth; and (2) proving added nutrients and a surface for attachment will promote rapid biomass growth and accumulation.

\subsection{Objectives}

The objectives of this thesis are:

- Identify the canal in the EAA with highest amount of chlorophyll to serve as the source of water. Chlorophyll is an indicator for microalgae biomass

- Identify the optimal nutrient combination for maximum culture growth

- Compare the resulting amount of biomass between a raceway pond system and a semi-submerged, immobilized cell system under natural conditions

o Determine if the addition of nutrients promotes biomass growth 
o Identify which system and nutrient treatment results in significantly larger amount of biomass.

- Compare the resulting amount of biomass between a raceway pond system and a semi-submerged, immobilized cell system under controlled, laboratory conditions

- Determine the effects of increased $\mathrm{pH}$ on biomass growth and culture contaminants

The information obtained from this study may serve to support the use of EAA water for the production of biofuels. 


\section{LITERATURE REVIEW}

\subsection{Everglades Agricultural Area}

The EAA is a 280,000-hectare tract of land located in South Florida between Lake Okeechobee, Water Conservation Areas (WCAs) and Everglades National Park. It includes four Florida counties: Palm Beach, Martin, Hendry and Glades. The EAA is one of the most active agricultural lands in the United States (Izuno, et al., 1992). It is composed of 9 basins, 15 major canals, and 25 water control structures or levees (Cooper, 1989). The primary system of canals and levees were designed by the U.S .Army Corps of Engineers to provide flood protection, water control, agricultural water supply for the nearby farms and those in Palm Beach, Broward and Miami Dade counties, and to maintain optimum groundwater levels to prevent saltwater intrusion (Cooper, 1989). However, the South Florida Water Management District oversees the day-to-day and maintenance of all pumps and canals in the area.

About fifty percent of the irrigation water in the EAA comes from canal water (Khanal, 1982). Water from Lake Okeechobee is diverted through canals where is pumped onto fields. Excess water is then returned to canals where the water flows directly into the WCAs carrying elevated levels of nutrients (Chimney \& Goforth, 2001). Utilizing this water as a base medium for algae growth represents an opportunity to lower the nutrient load entering the Everglades and avoid competition with fresh water supplies. 


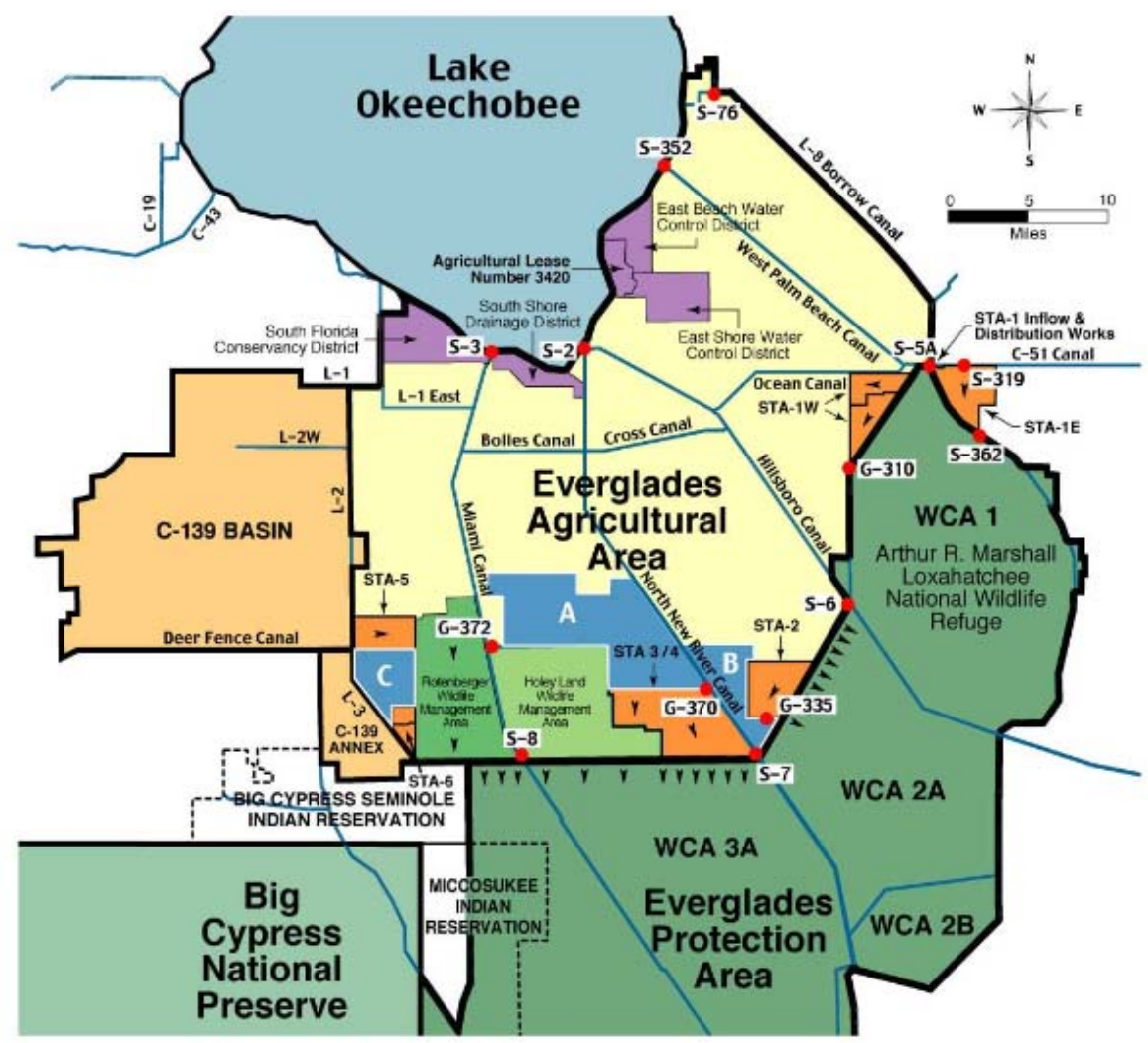

Figure 1. Everglades Agricultural Area (South Florida Water Management District)

\subsection{Biofuels}

The term biofuels refers to a fuel product derived from renewable biological material (EPA, 2012). In the U.S., the most common biofuels are ethanol, an ethyl alcohol that is prepared by fermenting simple sugars; and biodiesel, defined by the American Society for Testing and Materials (ASTM) as monoalkyl esters of long chain fatty acids derived from a renewable lipid feedstock, such as vegetable oil animal fat (Berrios, et al., 2010). Although not as popular, bio-butanol is an alcohol with a 4-carbon structure, and it is considered a superior liquid fuel with a potential to replace gasoline (Harvey and Meylemans, 2011). 


\subsubsection{First Generation Biofuels}

The first generation biofuels are those derived from sugars, starch, vegetables oils, and animal fats. Unfortunately, limitations in production capacity prevent these alternatives to meet all the transportation fuel needs (Christi, 2007). Specifically, intensive agricultural inputs, land use, and fresh water restrict their use (Sander \& Murthy, 2010). In the U.S., corn and soybean feedstock are grown almost exclusively on prime agricultural land in the Midwest, leaving by-products that are mostly used in animal feed, high fructose corn syrup, and other food additives. The use of this land sparks a serious moral issue that deals with global food supply. Known as the "food vs. fuel" debate, biofuel critics argued that the use of prime land in the U.S. for energy increases the price of food. Globally, that debate was exacerbated as developing countries, where not enough food is domestically produced, also use prime soil for the production of edible crops that are used for energy instead (Elobeid and Hart, 2007). Between 2005 and 2008, the World Bank estimated that the food price had increased by $83 \%$. As a result, 100 million people have fallen into poverty. In addition, it is estimated that the demand for biofuel crops contributed to $30 \%$ of that food price (World Bank, 2008). Moreover, a higher demand for crop yield fuels the use of intensive farming techniques, such as the extensive use of pesticides and fertilizers. In turn, these contribute to important environmental concerns such as soil erosion, loss of field fertility, and eutrophication of nearby bodies of water.

\subsubsection{Second Generation Biofuels}

Second generation biofuels are those made from cellulose and lignocellulose, and they are obtained from non-edible crops or waste biomass such as corn stover, corncobs, 
straw, wood, and wood byproduct. While second generation biofuels ease the tension of the "food vs. fuel" debates, some concerns are still significant. To start, biofuel critics are concerned with land conversion, displacement effects, and biodiversity loss that may occur, even if non-edible crops are used for the production of fuels. In addition, concerns about carbon mobilization as a product of the removal natural vegetation, and ecosystem alteration as a result of nutrient emission are associated with second generation biofuel (Christy, 2007). Lastly, land conversion may increase the risk of invasion by exotic species. However, when crops are grown in marginal lands, formerly intensively used agricultural sites, or superfund sites, the production of biofuels can have positive impacts (Midler, et al., 2008). Moreover, lignocellulose ethanol can reduce the greenhouse gas emissions by ninety percent (Lang, et al., 2001). Unfortunately, extracting fermentable sugars that are locked in cellulose and lignocellulose is a financially expensive as well as a technically challenging process. Currently, second generation biofuels are not produced commercially, but research and development continue to grow in the field.

\subsubsection{Third generation Biofuels}

Third generation biofuels are those produced from algae. Because algae are among the most photosynthetically efficient organisms on earth, a lot of interest has grown on their potential for biofuel production (Halim, et al., 2011). Algae have several advantages over conventional crops. Because of their simple cellular structure, algae have higher rates of biomass and oil production than other conventional crops (Becker, 1994). The per-unit area of oil is estimated to be around 18,000 to 75,000 U.S. liters per acre per each year (Maryking, 2007; Naredar, 2010). In addition, microalgae have much faster growth rates compared to terrestrial crops, which makes the collection of biomass more 
efficient. In addition, algae use less water than traditional crops and can be grown in marginal areas, thus ensuring there is no competition with food crops (Tsukahara \& Sawayama, 2005). Moreover, algae can efficiently sequester $\mathrm{CO}_{2}$, reducing the emission of greenhouse gas (Wang et al., 2010). A variety of high value biofuels are produced from commercial scale cultivation of microalgal biomass. The promising future of third generation biofuels has drawn public and private investment. More recently, The U.S. Energy Efficiency and Renewable energy department (EERE) announced the support of research projects aimed at boosting the productivity of algae cultivation systems. Unfortunately, although the number of pilot projects in the U.S. is increasing, a streamlined process has not been established for commercial production. In addition, research addressed by the United Nations cited fresh water supply and energy intensification for algae growth to be major concerns for third generation biofuels (Waltz, 2013).

As a result of the above mentioned advantages and concerns, algae fuels were chosen as the subject of research. My research investigated the use of canal water, specifically from the Everglades Agricultural Area (EAA), as a base medium and source of algae for the production of third generation biofuels.

\subsection{Types of Biofuels}

\subsubsection{Ethanol}

Ethanol, the world's most popular biofuel, is obtained through the fermentation of sugars (Sun and Cheng, 2002). While it can be produced from any feedstock that contains plentiful natural sugars, in the U.S., it is processed almost exclusively from corn. For this, the grain is processed to remove the sugar in wet and dry mills via crushing, soaking, 
and/or chemical treatment first. Next, the sugar is fermented, and the resulting mix is distilled and purified (EIA, 2007). Major byproducts from the ethanol production process include dried distillers' grains and solubles, which can be used as animal feed. On a smaller scale, corn gluten meal, gluten feed, corn oil, $\mathrm{CO}_{2}$, and sweeteners are also byproducts of the ethanol production (EIA, 2007). Although ethanol is primarily derived from corn, there are more advanced methods of production that can be used to obtain the fuel from cellulosic material such as switch grass, rice straw, and bagasse.

The biggest use of ethanol as a fuel in the U.S. is as an additive to gasoline, specifically to oxygenate gas, thus reducing the amount of carbon monoxide and ozone released when burned. It is added up to ten percent in by volume for E10 fuel. In addition, it is an alternative to gasoline in specially designed vehicles (Yacobucci, 2007). Despite the growing interest in biofuel it is still only a small component of the motor fuels consumed in the U.S., only representing five percent of the total fuel consumption in 2010 (Schnepf, 2011). Unfortunately, recent work suggest that the blend of ethanol and gasoline may worsen local air quality and negatively impact human health (Jacobson, 2007).

\subsubsection{Biodiesel}

According the American Society for Testing and Materials (ASTM), biodiesel is defined as monoalkyl esters of long chain fatty acids derived from a renewable lipid feedstock, such as vegetable oil or animal fat (Berrios, et al., 2010). Transesterification with an alcohol and an acid catalyst is the most common way to manufacture this biofuel (Berrios, et al., 2010). Also known as alcoholysis, transesterification refers to the displacement of an alcohol from an ester by another alcohol (Meher, et al., 2006). In the 
U.S., the most common crop utilized for the production of biodiesel is soybean (EIA, 2007). While biodiesel shares many similarities with conventional diesel, it has different

chemical, handling, and combustion properties (EIA, 2007). Most commonly, biodiesel is mixed with its petroleum counterpart in order to make B2, B5, and B20 blends, where each number represents the percentage of biodiesel included in the blend (EIA, 2007). The use of biodiesel has many advantages. To start, it is safer than conventional diesel as it contains lower sulfur and polyaromatic hydrocarbons (PAHs) than its counterpart. This is important considering that sulfur emissions are a significant source of acid rain and PAHs are known to be carcinogenic (Wedel, 1999). Next, biodiesel has a higher cetane number, which means it ignites faster than conventional diesel; thus, providing a possible advantage in very cold climates. Moreover, biodiesel oxygenation makes it a better lubricant for engines than conventional diesel

\subsubsection{1-Butanol}

Butanol (1-Butanol), also called butyl alcohol, is an alcohol with a 4-carbon structure, and its molecular formula is $\mathrm{C}_{4} \mathrm{H}_{10} \mathrm{O}$. It is an important industrial chemical and superior fuel with the potential to become a replacement for gasoline (Jang, et al., 2012). It is estimated that three hundred and fifty million gallons of butanol are sold every year, two hundred and twenty of those are sold in the U.S. (Shapovalov \& Ashkinazi, 2008). As an industrial chemical, butanol is used for the synthesis of acrylate and methacrylate esters as well as butyl acetate and butyl glycol. Moreover, it is used for the synthesis of butyl amines and aminoresins. Other uses included paint thinner, extracting agent during drug, alkaloid, antibiotic, camphor, hormone, as well as vitamin production, detergent additive, mobile phase in paper as well as thin-layer chromatography, and polishing 
additive (Schiel-Bengelsdorf, 2013). Butanol can be derived from fossil fuels or as the product of fermentation. The history of the biological production of butanol dates back to Louis Pasteur. In 1867, he described the alcohol as a product of fermentation in one of his cultures (Durre, 2007). Later, in 1916, ABE (acetone, butanol, ethanol) fermentation was used in the industrialization of butanol production. The method utilized the bacterial species Clostridium acetobutylicum, and ABE derived butanol was produced from a variety of sources such as corn, sugar beets, sugarcane, potatoes, tapioca and millet (Jang, et al., 2012)

The use of butanol as a biofuel is very recent. It was first documented in 2005, when David Ramey drove an unmodified motor vehicle across the country using butanol as a fuel (Durre, 2007). Since, butanol has gained popularity as a replacement for ethanol as a gasoline additive. The main reason for butanol's rise over ethanol is because butanol contains more energy than ethanol: 110,000 British Thermal Units (BTUs) compared to the 84,000 BTUs per gallon of ethanol (Shapovalov \& Askinazi, 2008). Moreover, the low water solubility of butanol could minimize the co-solvency concern currently associated with ethanol, consequently decreasing microbial-induced corrosion in fuel tanks and pipelines during transportation. Furthermore, butanol is less evaporative than gasoline or ethanol, making it a safer fuel than the others as it generates fewer volatile organic compounds (VOC) emissions (Durre, 2007). Finally, butanol is known to increase water uptake in a hydrocarbon fuel; this means that when added to gasoline, butanol can increase the octane rating and decrease the emission of nitrogen oxides (Black, et al., 2010). 


\subsubsection{ABE Fermentation}

The Acetone, Butanol, Ethanol (ABE) fermentation refers to the process in which bacteria from genus Clostridium converts starch into acetone, butanol, and ethanol in the ratios $3: 6: 1$, respectively. $\mathrm{ABE}$ fermentation is one of the oldest industrial processes for the production of butanol, and the second largest, by the yield of product, of ethanol production (Shapovalov \& Askinazi, 2008). Although butanol is currently manufactured using fossil fuels, in 2005, Dupont and British Petroleum (BP) stated their intentions to restart industrial scale $\mathrm{ABE}$ fermentation for the production of biofuels (Kumar \& Gayen, 2011). ABE fermentation is characterized by two stages: acidogenesis and solventogenesis (Ellis, et. al., 2012). In the former stage, fermenting bacteria produce butyric, propionic, lactic, and acetic acids. Then, the $\mathrm{pH}$ decreases to about 4.5 , which triggers a metabolic shift to the solventogenesis stage (Shapovalov \& Askinazi, 2008). In the solventogenesis step, solvent production occurs, resulting in the formation of butanol, acetone, and ethanol (Durre, 2007). Current research on ABE fermentation focuses on increasing yields, microbial strain improvement and resistance, and exploration if new possible feedsctock. Unfortunately, economic studies on the feasibility of butanol demonstrated that a switch to this biofuel may not be currently possible (Kumar \& Gayen, 2011). Because feedstock accounts for sixty percent of the total production cost and in order to increase the production of butanol through $\mathrm{ABE}$ fermentation, four hundred millions bushels of corn (or equivalent crop) will be required per year in the U.S., a switch to butanol is not currently possible (Shapovalov \& Askinazi, 2008). In order to make butanol cost competitive, an alternative feedstock needs to be explored. 


\subsection{Use of Algae as Feedstock for Biofuels}

Algae are highly diverse group of organisms that have important functions in aquatic habitats (Round, 1984). More specifically, they are an evolutionarily diverse group of photoautotrophic organisms that possess chlorophyll $a$ and $b$ and unicellular reproductive structure (Round, 1984). Although they have a common metabolism, they vary in shape in size (Rogers \& Gallon, 1988). In general terms, there are two types of algae - microalgae and macroalgae. Microalgae are very small, and their size range from $1-50 \mu \mathrm{m}$ (Chang, 2007). Macroalgae, by contrast, can reach up to $120 \mathrm{~cm}$ in length (Mchugh, 2003). Algae through the process of photosynthesis assimilate $\mathrm{CO}_{2}$ in the atmosphere as a carbon source for growth and they produce about fifty percent of the oxygen on Earth (Chapman, 2013). Algae are extremely important as they are the primary food source upon which all aquatic life, both marine and freshwater, depends on (Chapman, 2013). Moreover, algae are known to be capable of switching from carbohydrate accumulation to intracellular lipids accumulation (Vijayaraghavan \& Hemanathan, 2009), and these are important qualities when examining them for fuel production.

Phycologists have classified microalgae in a variety of classes, primarily differentiated by their pigmentation, life cycle, and basic cellular structure. The most important classes are (Borowitzka 1997):

i. Diatoms (Bacillariophyceae) are mainly dominant phytoplankton of ocean, but are also found in fresh and brackish water, and store carbon in the form of natural oil or as a polymer of carbohydrate. They use silica to build their cell 
wall, and this structure makes them useful in the manufacturing of pool filters (Chapman, 2013)

ii. Green algae (Chlorophyceae) are a diverse group from which higher plants evolved (Stevenson, et al., 1996). They are commonly found in fresh water and swimming pools. It is estimated that there are between six thousand and eight thousand species in this group, and ninety percent of them inhabit in fresh water (Chapman, 2013). Green algae store their energy in the form of form of starch, but oils can also be formed under certain growth conditions. Because of their strong presence in fresh water, green algae species are favored for the production of biofuels.

iii. Golden algae (Chrysophyceae) can be yellow, orange or brown in color and they produce natural oil and carbohydrates as storage compounds.

Separately, blue-green algae (Cynophyceae), organisms that are much closer to bacteria, are prokaryotes present in almost every conceivable habitat and play an important role in nitrogen fixation from atmosphere. My research will utilize the organisms present in canal water from the EAA; thus a consortium of algae and cyanobacteria is expected.

\subsubsection{Mass Production of Algae}

The production of algal biomass is very challenging and more expensive than growing crops. While algae are fast metabolizers, photosynthetic growth requires sufficient light, abundant carbon dioxide, water, inorganic salts, and favorable temperature (Christi, 2007). Because light does not penetrate more than a few centimeters into a dense algae culture, the main issue with large scale production involves increasing 
surface area, rather than volume (Scott, et al., 2010), and because the optimum temperature for algae growth is between 20 and $30^{\circ} \mathrm{C}$. (Wan, et al., 2011), mass production is not possible in all regions or during all seasons. Keeping these requirements in mind, two major pathways of growth have been favored: raceway ponds and photobioreactors.

\section{Open ponds:}

Raceway ponds are the oldest systems used in the mass cultivation of algae. They have been utilized since the 1950s for mass culture of microalgae in the food industry (Christi, 2007). They are inexpensive to build and relatively easy to operate (Scott, et. al., 2010). They vary in size, shape, type of agitation, inclination, and construction material (Tredici, 2004). Typically, a raceway pond consists of a closed loop recirculation channel of about $0.3 \mathrm{~m}$ deep, where mixing and circulation are produced by a paddlewheel continuously (Christi, 2007). Raceway pond cultures require greater quantities of water as substantial amounts are lost to evaporation. In addition, there are concerns regarding contamination, competition, and inefficient use of carbon dioxide (Christi, 2007). In response to the concerns raised by raceway ponds, photobioreactors were developed.

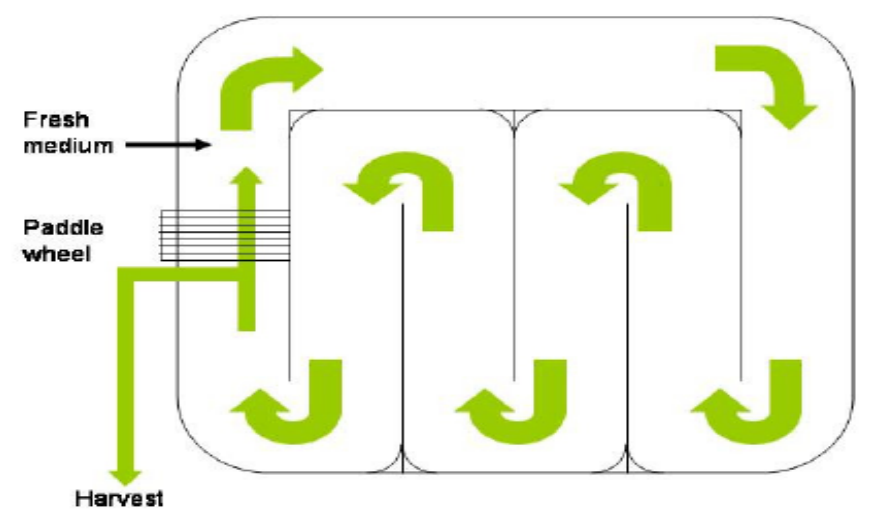

Figure 2: Schematic Diagram of an Open Pond (Christi, 2007) 


\section{Enclosed Photobioreactors:}

While many prototypes have been completed, tubular reactors are the most accepted style. These consist of an array of straight transparent tubes, usually $0.1 \mathrm{~m}$ in diameter connected to a reservoir, where materials constantly circulate through (Chisti, 2007). The water circulation is powered by a mechanical pump or by air-lift (Scott, et al., 2010). The two most important advantages of implementing this culture method are the avoidance of contamination and the ability to have single-species cultures. In addition, biomass harvest is less expensive than open ponds, because the algal biomass is about 30 times as concentrated as the biomass in the open ponds (Chisti, 2007). However, their manufacturing is energy demanding and expensive (Scott, et al., 2010). In spite of these drawbacks, photobioreactors still receive support because of their small space requirements and their ability to optimize cultures of high oil yielding species to reach production of over 200 times the yield from the best-performing plant or vegetable oil (Demirbas \& Demirbas, 2011).

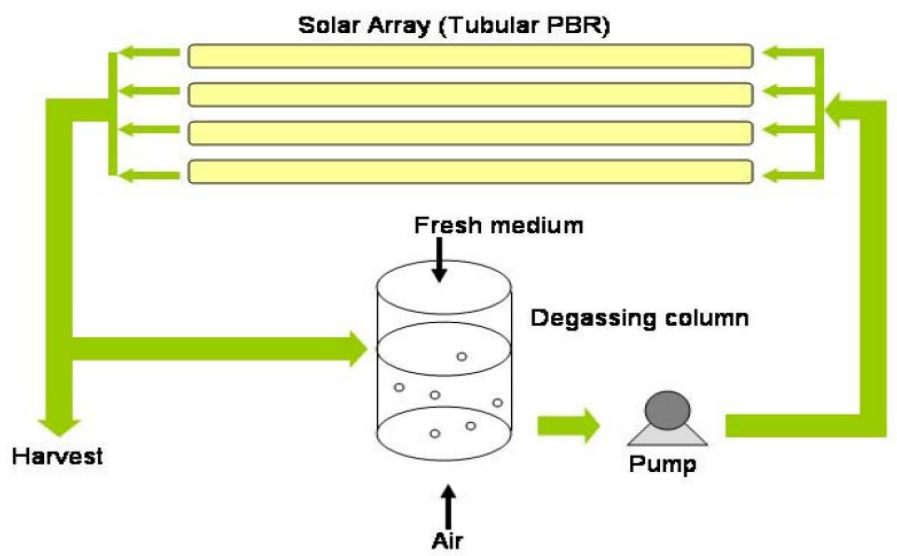

Figure 3: Schematic Diagram of an Enclosed Photobioreactor (Christi, 2007) 
Open ponds remain the most popular method of mass cultivation for algae, as capital and maintenance cost prohibit photobioreactor $\mathrm{s}$ to be competitive. This research will compare a typical raceway pond with an open suspended rotary system. The experimental system can cut operating cost in batch operations if yield is improved.

\subsection{Water and Algae Production}

Although the algal biofuels diminish the "food vs. fuel" conflict typically associated with the notion of biofuel production, they still impose a great challenge in water management. It is generally understood that production of biomass for energy is a consumptive use of water that may directly compete with food crop production (Berndes, 2002). According to a report published by National Academy of Science, 1 liter of algal biofuel requires up to 3,650 liters of freshwater (NRC, 2012). The amount of water required for biofuel production is alarming when considering the 1.2 billion people that lack access to clean water for domestic use (WHO, 2003). Moreover, while water is physically scarce in Central and West Asia and North Africa at present time, it is estimated that over the next several decades two thirds of the world population will be affected over water scarcity (Rijsberman, 2004). Hydrologists assess physical water scarcity by examining the population-water equation where an area will be considered stressed if annual water supplies drop below $1000 \mathrm{~m}^{3}$ per person (Gleik, 2008). According to this equation, Florida is not under physical water scarcity; however, fresh water supply may be impacted by saltwater intrusion, drought, and pressure from an increasing population. 
As a response for the concern of algal biofuels stress in fresh water supply, several authors have explored the use of wastewater as a culture medium for algae production; specifically, algae obtained from water treatment plants has been proposed for anaerobic digestion. (Oswald and Gotaas, 1957; Goldman, 1979; Soedes, 1980; Udoma, et al., 2012; Yuan, et al., 2012; Christenson \& Sims, 2011). The potential use of algae obtained from water treatment plants is important for biofuel economics as algae are a bi-product of nutrient mitigation operations; thus, also reducing the feedstock cost. However, while this can be presented as a great solution for agricultural runoff, the installation of bioreactors may not be an affordable solution for farmers implanting best management practices. Thus, the use of raceway ponds should be explored. 


\section{METHODS}

\subsection{Assessment of Canal Water Suitability for Algae Growth}

A survey was conducted during July 2013 in the EAA canals in order to determine the availability of algae in the canals that can be augmented. The objective to this survey is to determine the best suitable canal in the EAA as a source of nutrient rich water to be used for subsequent experiments. The amount of chlorophyll found in the water was used as an indicator of algal biomass present.

Seventeen different canals and levees were sampled in the EAA: L-8, L-12, L-13, L-14 (part of the Hillsborough canal), L-19 (part of the North New River canal), L-20 (part of the North New River canal), L-21, C-6 (Miami Canal), an unmarked levee on Teddar Road, and unmarked levee on Gator Road, a small canal marked " 411 ” on county road 880 , and a canal leading to water pump G2. In addition, an outflow canal for pumping station 308S, and an unmarked canal that borders Loxahatchee National Wildlife Refuge were sampled. Sampling was completed over a period 48 hours.

From each canal, 3 separate surface water samples of $500 \mathrm{~mL}$ each were collected for filtering. For this, a 9.6-Volt portable and rechargeable submersible utility pump (AquaCharge, Model \# AQ500-100) was used. Each sample was filtered using a Whatman GF/A fiber glass filter $(1.6 \mu \mathrm{m})$ in order to trap planktonic microorganisms. Each filter was stored in the dark, cooled and taken to the lab for chlorophyll extraction. 


\section{Sampled Sites in the EAA}

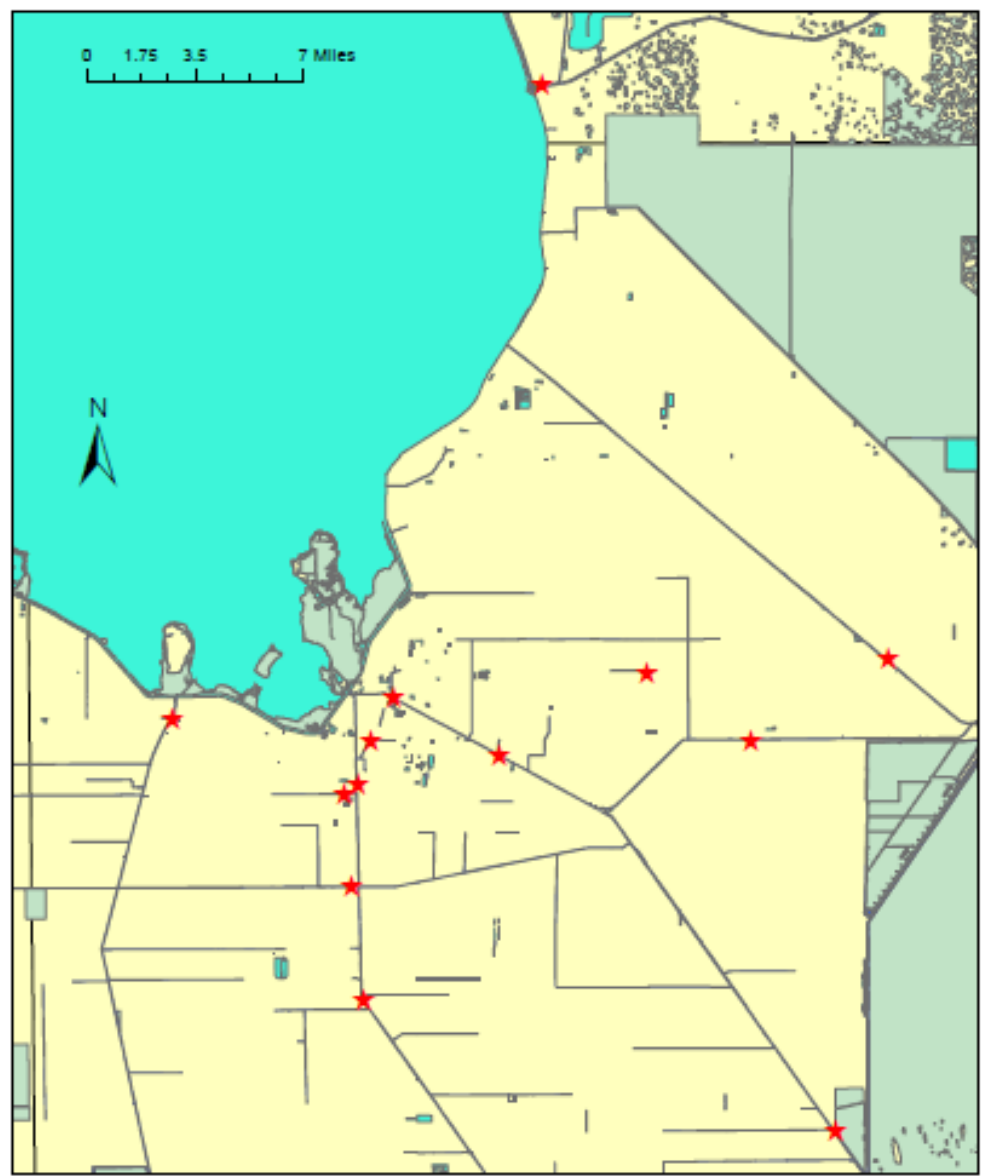

Figure 4. EAA canals sampled in July 2013

Sample processing procedure for chlorophyll extraction was adapted from Dere, et al., (1997). Each filter was placed in a $15 \mathrm{~mL}$ conical Falcon tube, and $5 \mathrm{~mL}$ of $100 \%$ acetone (Fisher) was added. Tubes were covered in aluminum foil and stored at $4{ }^{\circ} \mathrm{C}$ for 24 hours.

Next, samples were centrifuged at $5000 \mathrm{rpm}$ for 10 minutes. Supernatant was transferred into a $2 \mathrm{~mL}$ cuvette. Absorbance was measured at $662 \mathrm{~nm}$ and $646 \mathrm{~nm}$ for chlorophyll $a$ and $b$, respectively, using a Thermo Scientific Spectromic 200 photospectrometer. Readings were recorded and the amount of pigment was calculated 
according to the formulas of Lichtentaler and Wellburn (1984). The formulas are shown in Table 1.

\begin{tabular}{|l|l|}
\hline Chlorophyll $a$ & $11.75 \mathrm{~A}_{662}-2.350 \mathrm{~A}_{645}$ \\
\hline Chlorophyll $b$ & $18.61 \mathrm{~A}_{645}-3.960 \mathrm{~A}_{662}$ \\
\hline Total Chlorophyll & $\mathrm{Ca}+\mathrm{Cb}$ \\
\hline
\end{tabular}

Table 1. Formulas used in the calculation of pigments

\subsection{Assessment of Different Growth Media}

The sampling site with the highest amount of chlorophyll found (LOX) was selected for this experiment. Two additional sites, Station Pump S308 and the MC canal were selected following recommendation of SFWMD's staff. The objective of the experiment is to identify an optimal media that augments algal biomass growth across the EAA. Thus, its components will be used to supplement the canal water used in subsequent experiments.

Three selective media were prepared as per Andresen (2005). The media were prepared without recipe modification and mixed in a 1:1 ratio with canal water, making the media half-strength. The total volume of the samples was $60 \mathrm{ml}$, and they were kept in $125 \mathrm{ml}$ Erlenmeyer flasks capped with foam stoppers. The cultures were grown in an incubator shaker (New Brunswick Scientific Excella E24) at $150 \mathrm{rpm}$ and $25^{\circ} \mathrm{C}$ for 21 days. Light source consisted of LED bulbs with a $380 \mathrm{~lm}$ intensity (LED bulbs, 8.5-watt, efficacy $45 \mathrm{~lm} /$ watt, $3000 \mathrm{~K}$ warm color temperature, high CRI 84).

To determine the best suitable media, algal biomass was quantified via chlorophyll levels present in the cultures and total dried weight. The total chlorophyll 
present in the cultures was quantified by collecting $5 \mathrm{~mL}$ of each sample and filtering it using a Whatman GF/A filter. Chlorophyll extraction and quantification was adapted from Dere, et al., (1997) and executed as per section 3.1. In addition, total biomass present was obtained by filtering the cultures using a Whatman GF/A filter on the $21^{\text {st }}$ day. Filter weight was recorded before filtering and 48 hours after filtering, allowing time for them to dry. Weight change was recorded and noted as algal biomass. The three locations and media were compared, and the one demonstrating the greatest amount biomass accumulated was selected as source for the subsequent experiments.

\subsubsection{Media Preparation}

The media used in this experiment were chosen for their selectivity of green algae and accessibility of materials. All solutions were prepared by dilution into $1000 \mathrm{~mL}$ of deionized water, mixed to homogeneity and sterilized at $121^{\circ} \mathrm{C}$ for 15 minutes. The chosen recipes were prepared as broth and are as follows (Andersen, 2005):

\section{- Chu Medium:}

This is a synthetic medium that is designed to mimic lake water. Thus, it is used to grow a variety of algae, including green algae, diatoms, and cyanobacteria.

\begin{tabular}{|c|c|c|c|}
\hline Component & $\begin{array}{c}\text { Stock Solution } \\
\left(\mathbf{g}^{-} \mathbf{L}^{-1} \mathbf{d H}_{\mathbf{2}} \mathbf{O}\right)\end{array}$ & $\begin{array}{c}\text { Quantity } \\
\text { Used }\end{array}$ & $\begin{array}{c}\text { Concentration in } \\
\text { Final medium } \\
\text { (M) }\end{array}$ \\
\hline $\mathrm{Ca}\left(\mathrm{NO}_{3}\right)_{2}$ & 40.0 & $1 \mathrm{~mL}$ & $2.44 \times 10^{-4}$ \\
\hline $\mathrm{K}_{2} \mathrm{HPO}_{4}$ & 5.0 & $1 \mathrm{~mL}$ & $2.87 \times 10^{-5}$ \\
\hline $\mathrm{MgSO}_{4} \cdot 7 \mathrm{H}_{2} \mathrm{O}$ & 25.0 & $1 \mathrm{~mL}$ & $1.01 \times 10^{-4}$ \\
\hline $\mathrm{Na}_{2} \mathrm{CO}_{3}$ & 20.0 & $1 \mathrm{~mL}$ & $1.89 \times 10^{-4}$ \\
\hline $\mathrm{Na}_{2} \mathrm{SiO}_{3}$ & 25.0 & $1 \mathrm{~mL}$ & $2.05 \times 10^{-4}$ \\
\hline $\mathrm{FeCl}_{3}$ & 0.8 & $1 \mathrm{~mL}$ & $4.93 \times 10^{-6}$ \\
\hline
\end{tabular}

Table 2. Chu Medium Recipe. 


\section{- DyIII Medium}

This medium is based on concentrations of anions and cations present in a pond during exponential growth.

\begin{tabular}{|c|c|c|c|}
\hline Component & $\begin{array}{l}\text { Stock Solution } \\
\left(\mathrm{g} \cdot \mathrm{L}^{-1} \mathrm{dH}_{2} \mathrm{O}\right)\end{array}$ & $\begin{array}{l}\text { Quantity } \\
\text { Used }\end{array}$ & $\begin{array}{l}\text { Concentration in } \\
\text { Final medium } \\
\text { (M) }\end{array}$ \\
\hline MES Buffer & - & $200 \mathrm{mg}$ & $1.02 \times 10^{-3}$ \\
\hline $\mathrm{CaCl}_{2} \cdot 2 \mathrm{H}_{2} \mathrm{O}$ & 75.00 & $1 \mathrm{~mL}$ & $5.10 \times 10^{-4}$ \\
\hline $\mathrm{NaSiO}_{3} \cdot 9 \mathrm{H}_{2} \mathrm{O}$ & 15.00 & $1 \mathrm{~mL}$ & $5.28 \times 10^{-5}$ \\
\hline $\mathrm{MgSO}_{4} \cdot 7 \mathrm{H}_{2} \mathrm{O}$ & 50.00 & $1 \mathrm{~mL}$ & $2.03 \times 10^{-4}$ \\
\hline $\mathrm{NH}_{4} \mathrm{NO}_{3}$ & 5.00 & $1 \mathrm{~mL}$ & $6.25 \times 10^{-5}$ \\
\hline $\mathrm{NaN} \mathrm{O}_{3}$ & 20.00 & $1 \mathrm{~mL}$ & $2.35 \times 10^{-4}$ \\
\hline $\mathrm{KCl}$ & 3.00 & $1 \mathrm{~mL}$ & $4.02 \times 10^{-5}$ \\
\hline $\begin{array}{c}\mathrm{Na}_{2} \beta- \\
\text { glycerophosphate }\end{array}$ & 10.00 & $1 \mathrm{~mL}$ & $4.63 \times 10^{-5}$ \\
\hline $\mathrm{H}_{3} \mathrm{BO}_{3}$ & 4.58 & $1 \mathrm{~mL}$ & $7.40 \times 10^{-5}$ \\
\hline $\begin{array}{l}\text { Trace Element } \\
\text { Solution }\end{array}$ & $\begin{array}{l}\text { (See following } \\
\text { recipe) }\end{array}$ & $1 \mathrm{~mL}$ & - \\
\hline Vitamin Solution & $\begin{array}{l}\text { (see following } \\
\text { recipe) }\end{array}$ & $1 \mathrm{~mL}$ & - \\
\hline \multicolumn{4}{|c|}{ Trace Element Solution } \\
\hline $\mathrm{Na}_{2}$ EDTA & - & $8.000 \mathrm{~g}$ & $2.74 \times 10^{-5}$ \\
\hline $\mathrm{Fe}$ & - & $0.700 \mathrm{~g}$ & $1.25 \times 10^{-5}$ \\
\hline $\mathrm{MnCl}_{2} \cdot 4 \mathrm{H}_{2} \mathrm{O}$ & - & $0.720 \mathrm{~g}$ & $3.64 \times 10^{-6}$ \\
\hline $\mathrm{ZnSO}_{4} \cdot 7 \mathrm{H}_{2} \mathrm{O}$ & - & $0.176 \mathrm{~g}$ & $6.12 \times 10^{-7}$ \\
\hline $\mathrm{Na}_{2} \mathrm{MoO}_{4} \cdot 6 \mathrm{H}_{2} \mathrm{O}$ & 50 & $1 \mathrm{~mL}$ & $2.08 \times 10^{-7}$ \\
\hline $\mathrm{CoCl}_{2} \cdot 6 \mathrm{H}_{2} \mathrm{O}$ & 29 & $1 \mathrm{~mL}$ & $1.22 \times 10^{-7}$ \\
\hline \multicolumn{4}{|c|}{ Vitamin Solution } \\
\hline $\mathrm{C}_{12} \mathrm{H}_{17} \mathrm{~N}_{4} \mathrm{OS}$ & - & $200 \mathrm{mg}$ & $5.93 \times 10^{-7}$ \\
\hline $\mathrm{C}_{10} \mathrm{H}_{16} \mathrm{~N}_{2} \mathrm{O}_{3} \mathrm{~S}$ & 0.5 & $1 \mathrm{~mL}$ & $2.05 \times 10^{-9}$ \\
\hline $\mathrm{C}_{63} \mathrm{H}_{88} \mathrm{CoN}_{14} \mathrm{O}_{14} \mathrm{P}$ & 0.5 & $1 \mathrm{~mL}$ & $3.69 \times 10^{-10}$ \\
\hline
\end{tabular}

Table 3. Recipe for DyIII Medium. 


\section{- WC Medium}

Although this medium is used particularly for the cultivation of cryptophytes, it is known to support of the growth of some cyanobacteria and a wide array of chlorophytes. This medium was selected for its slightly alkaline condition ( $\mathrm{pH} 8)$, which is similar to the $\mathrm{pH}$ of Lake Okeechobee and its tributaries.

\begin{tabular}{|c|c|c|c|}
\hline Component & $\begin{array}{c}\text { Stock Solution } \\
\left(\mathrm{g} \cdot \mathrm{L}^{-1} \mathbf{d H}_{2} \mathrm{O}\right)\end{array}$ & $\begin{array}{l}\text { Quantity } \\
\text { Used }\end{array}$ & $\begin{array}{l}\text { Concentration in } \\
\text { Final Medium (M) }\end{array}$ \\
\hline Tris (buffer) & - & $500 \mathrm{mg}$ & $4.13 \times 10^{-3}$ \\
\hline $\mathrm{NaNO}_{3}$ & 85.01 & $1 \mathrm{~mL}$ & $1.00 \times 10^{-3}$ \\
\hline $\mathrm{CaCl}_{2} \cdot 2 \mathrm{H}_{2} \mathrm{O}$ & 36.76 & $1 \mathrm{~mL}$ & $2.50 \times 10^{-4}$ \\
\hline $\mathrm{MgSO}_{4} \cdot 7 \mathrm{H}_{2} \mathrm{O}$ & 36.97 & $1 \mathrm{~mL}$ & $1.50 \times 10^{-4}$ \\
\hline $\mathrm{NaHCO}_{3}$ & 12.60 & $1 \mathrm{~mL}$ & $1.50 \times 10^{-4}$ \\
\hline $\mathrm{Na}_{2} \mathrm{SiO}_{3} \cdot 9 \mathrm{H}_{2} \mathrm{O}$ & 28.42 & $1 \mathrm{~mL}$ & $1.00 \times 10^{-4}$ \\
\hline $\mathrm{K}_{2} \mathrm{HPO}_{4}$ & 8.71 & $1 \mathrm{~mL}$ & $5.00 \times 10^{-5}$ \\
\hline $\begin{array}{l}\text { Trace element } \\
\text { Solution }\end{array}$ & $\begin{array}{l}\text { (See following } \\
\text { recipe) }\end{array}$ & $1 \mathrm{~mL}$ & - \\
\hline Vitamin Solution & $\begin{array}{c}\text { (See following } \\
\text { recipe) }\end{array}$ & $1 \mathrm{~mL}$ & - \\
\hline \multicolumn{4}{|c|}{ Trace Elements Solution } \\
\hline Na2 EDTA & - & $4.36 \mathrm{~g}$ & $1.17 \times 10^{-5}$ \\
\hline $\mathrm{FeCl}_{3} \cdot 6 \mathrm{H}_{2} \mathrm{O}$ & - & $3.15 \mathrm{~g}$ & $1.17 \times 10_{-}^{5}$ \\
\hline $\mathrm{CuSO}_{4} \cdot 5 \mathrm{H}_{2} \mathrm{O}$ & 10.0 & $1 \mathrm{~mL}$ & $4.01 \times 10^{-8}$ \\
\hline $\mathrm{ZnSO}_{4} \cdot 7 \mathrm{H}_{2} \mathrm{O}$ & 22.0 & $1 \mathrm{~mL}$ & $7.65 \times 10^{-8}$ \\
\hline $\mathrm{CoCl}_{2} \cdot 6 \mathrm{H}_{2} \mathrm{O}$ & 10.0 & $1 \mathrm{~mL}$ & $4.20 \times 10^{-8}$ \\
\hline $\mathrm{MnCl}_{2} \cdot 4 \mathrm{H}_{2} \mathrm{O}$ & 180.0 & $1 \mathrm{~mL}$ & $9.10 \times 10^{-7}$ \\
\hline $\mathrm{Na}_{2} \mathrm{MoO}_{4} \cdot 2 \mathrm{H}_{2} \mathrm{O}$ & 6.0 & $1 \mathrm{~mL}$ & $2.48 \times 10^{-8}$ \\
\hline $\mathrm{H} 3 \mathrm{BO}_{3}$ & - & $1.00 \mathrm{~g}$ & $1.62 \times 10^{-5}$ \\
\hline \multicolumn{4}{|c|}{ Vitamin Solution } \\
\hline Thiamine $\cdot \mathrm{HCl}$ & - & $100 \mathrm{mg}$ & $2.96 \times 10^{-7}$ \\
\hline Biotin & 0.5 & $1 \mathrm{~mL}$ & $2.05 \times 10^{-9}$ \\
\hline Cyanocobalamin & 0.5 & $1 \mathrm{~mL}$ & $3.69 \times 10^{-10}$ \\
\hline
\end{tabular}

Table 4. Recipe for WC medium 


\subsection{Different Systems for Biomass Growth}

Two different growing systems for outdoor mass cultivation of algae were tested. The objective of this experiment is to identify which system is superior for biomass production. The water used for this experiment was collected from the selected site (LOX). In June 2014, 350 liters of water were collected simultaneously, using a 9.6-Volt portable and rechargeable submersible utility pump (AquaCharge, Model \# AQ500-100), and transported to the study site. Artificial ponds or mesocosms were set-up using 20 plastic bins of $59.7 \times 42.9 \times 14.9 \mathrm{~cm}$ in the Center for Agroecology and Sustainable Agriculture (CASA) in Homestead, FL for 45 days between the months of July and August of 2014.

Half of the bins were used as raceway pond systems and the other half were used as semi-submerged, immobilized cell systems. The mesocosms were set up on the ground and left uncovered in order to be exposed to natural light, temperature changes, and precipitation. The top surface of each of the 20 bins was covered with a thin, light mesh fabric to exclude the debris and macrofauna. All mesocosms received full sun and were set up as per the diagram: 


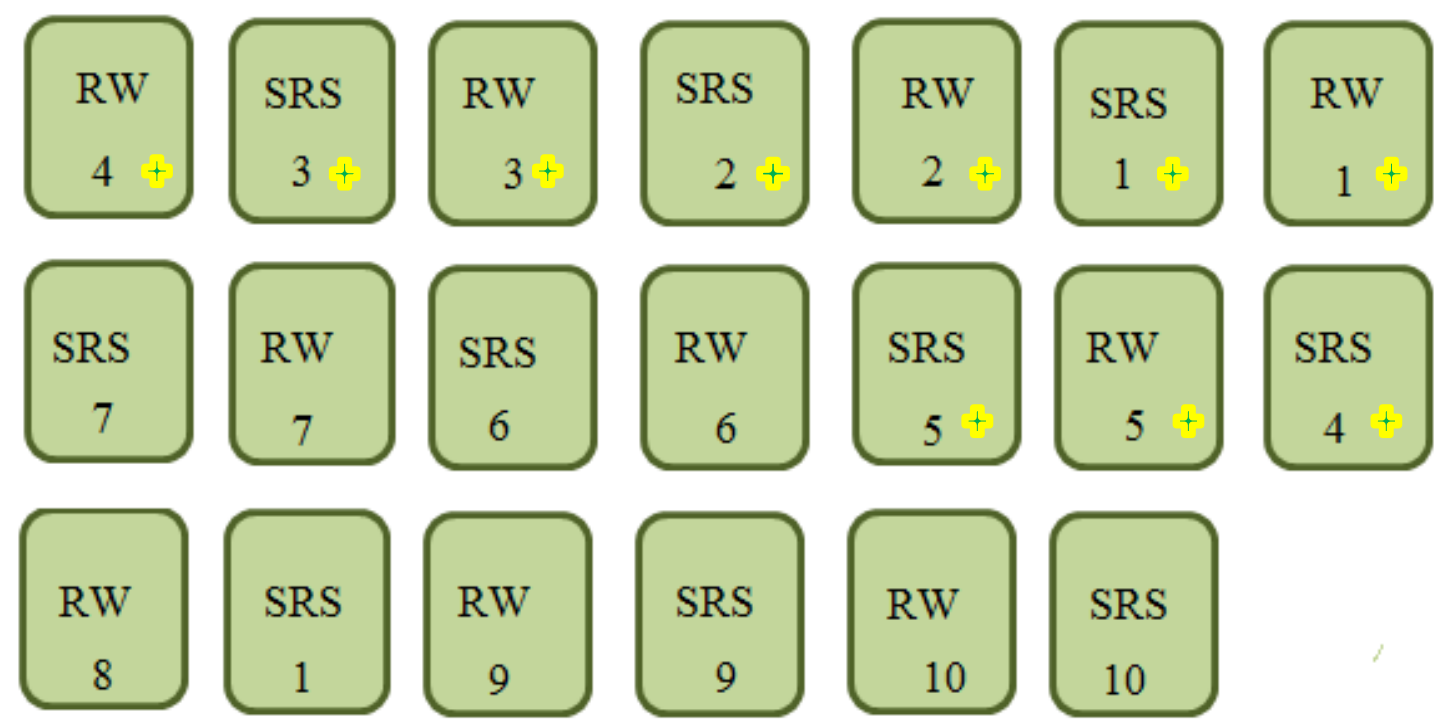

Figure 5. Raceway Pond (RW) and Suspended Rotary System (SRS) Mesocosm Set-Up. Bins marked with the yellow cross represent those that received a nutrient treatment

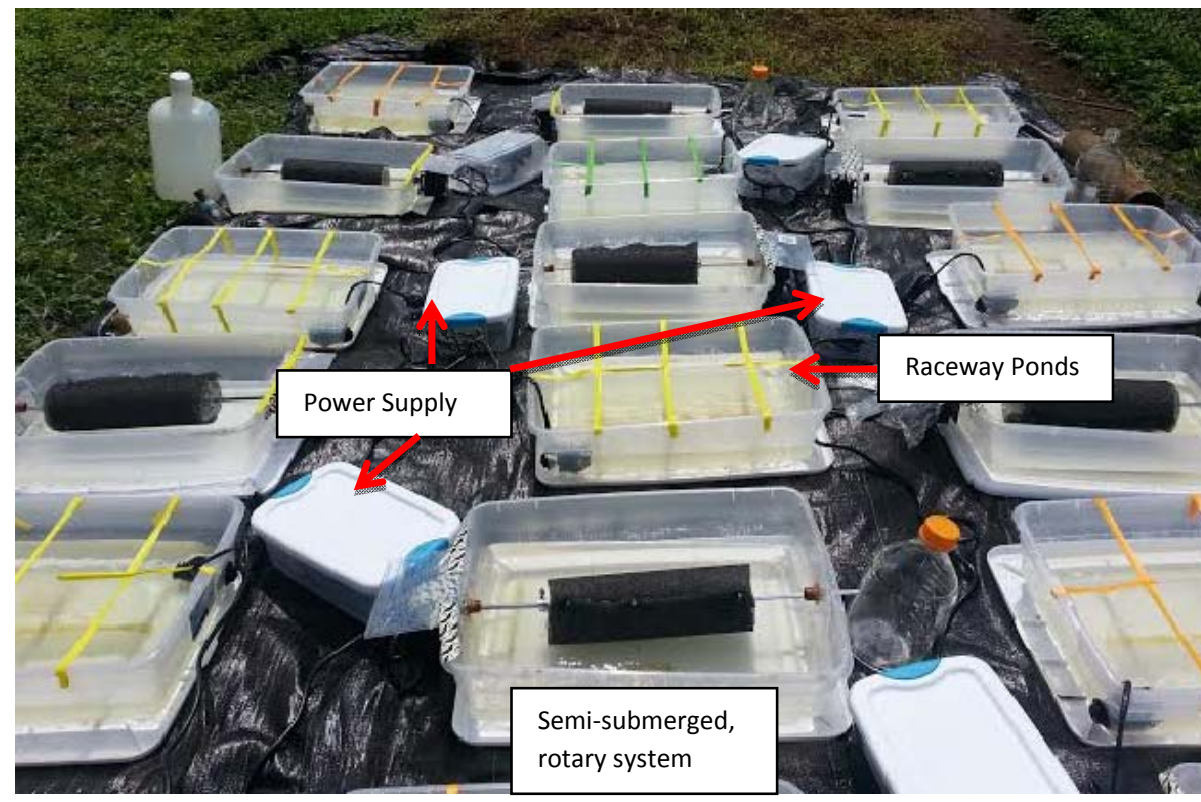

Figure 6. Mesocosms set-up at CASA

\subsubsection{Raceway Pond}

Typical raceway ponds were built using 10 bins. Each one of the bins consisted of a plexiglass sheet in the middle, and a submerged Hydor Koralia Nano 425-GPH 
aquarium circulation pump to keep the water constantly circulating. Figure 7 depicts the bins that were built to mimic a raceway pond. Out of the 10 bins, nutrients were added to the water of 5 bins following the Chu medium recipe that selected in experiment 3.2; thus, all the ingredients listed in table 2 were added per liter of water in the bins, allowing the water to have the full-strength medium concentration. To the other 5 bins, water was added without any amendment. Each plastic bin has a maximum capacity of 27 liters, but the water was kept at the 10 liter mark.

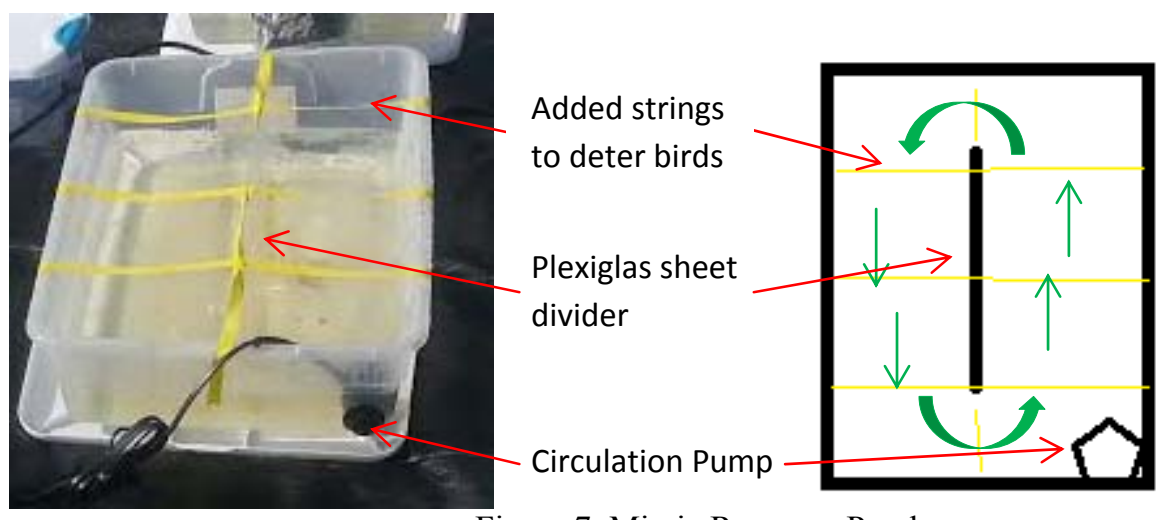

Figure 7. Mimic Raceway Pond

Excess rainwater accumulated in the ponds was removed every 5 days until the bins reached the 8 liter mark. In addition, 2 additional liters of water were removed. For the bins with the nutrient treatment, 2 liters of canal water supplemented with all Chu medium ingredients were added back into the bin. For the bins without the nutrient treatment, 2 liters of canal water were added without amendment into the bin. On the $45^{\text {th }}$ day of experiment, water was collected from the bins and transported back to Florida International University for biomass collection and dewatering 


\subsubsection{Semi-Submerged, Immobilized Algae Cell System}

The semi-submerged, immobilized system was build using 10 plastic bins. This experimental set up involves a rotating a PVC pipe, in which 1sq. ft. of Polytech ${ }^{\circledR}$ type $S$ reticulated foam was attached by 4 screws. The weight of the foam was used as the indicator of the biomass accumulated in it; thus, the initial foam weight was taken and recorded. The cylinder was powered by a $120 \mathrm{~V}$ motor, and its rotation allows the foam to be constantly aerated. Correspondingly to the raceway ponds, 5 of the plastic boxes used for the semi-submerged, rotary system received the nutrient treatment and the other $5 \mathrm{did}$ not, and all bins contained 8 liters of water.

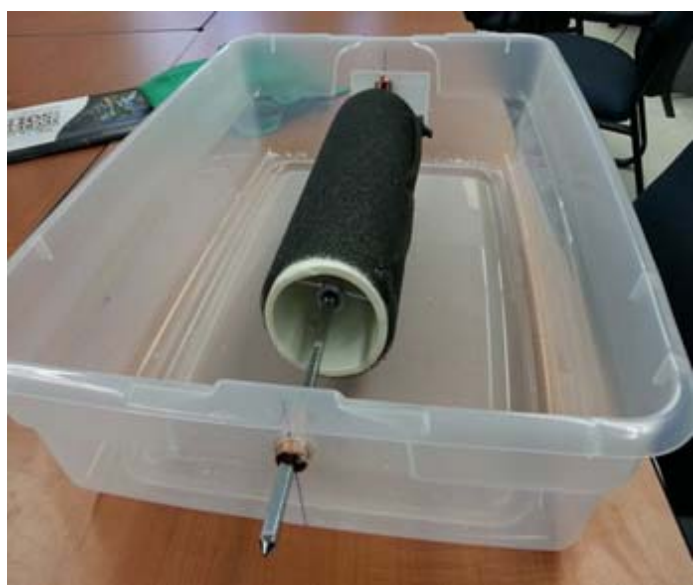

Figure 8. Semi-Submerged, Rotary System

Consistently with the raceway ponds, excess rainwater accumulated was removed every 5 days until the bins reached the 8 liter mark. Additional 2 liters of water were removed. For the bins with the nutrient treatment, 2 liters of canal water supplemented with Chu medium were added back into the bin. For the bins without the nutrient 
treatment, 2 liters of canal water were added without amendment into the bin. On the $45^{\text {th }}$ day of experiment, water was collected for processing, and the PVC pipe with the foam was collected and taken to the lab for drying and weight recording.

\subsubsection{Quantification of Biomass}

A Millipore Easy-Load Masterflex (model No.77410-10) peristaltic pump was used to harvest algal cells and obtain a biomass-rich water sample for all of the 20 bins. Next, water obtained from the bins was centrifuged using Beckman Coulter Avanti J-26S Series at 8,000rpm for 20 minutes, supernatant was discarded and the remaining algal biomass was stored in 50mL Falcon tubes and frozen. For the semi-submerged system, the foam was removed, oven dried, and weighted. The difference in weight was recoded as biomass accumulation.

Lyophilization was completed using a Virtis Bench Top Manifold freeze-dryer Freeze drying was used to eliminate any water. The algae obtained were placed in $50 \mathrm{~mL}$ Falcon tubes and were dried at $-82^{\circ} \mathrm{C}$ for 7 hours. Dried biomass weight was recorded for statistical comparison.

\subsection{The Use of Reticulated Foam for Algal Biomass Production}

In order to eliminate the influence of uncontrolled variables, the use of the reticulated foam was tested in laboratory conditions. For this, 20 samples of canal water collected from the LOX site were amended to reflect full-strength Chu medium. Each sample consisted of 50mL. Cultures were kept in a $125 \mathrm{~mL}$ capacity Erlenmeyer flask and incubated in a New Brunswick Scientific Excella E24 incubator shaker at $150 \mathrm{rpm}$ 
and $25^{\circ} \mathrm{C}$ for 45 days with continuous light at $380 \mathrm{~lm}$ of intensity (LED light bulbs - 8.5watt, efficacy $45 \mathrm{~lm} /$ watt, 3000K warm color temperature, high CRI 84).

To ten of the flasks, a 1sq. inch of Polytech ${ }^{\circledR}$ type $\mathrm{S}$ reticulated foam was added to 10 of the flasks. This ester-based foam is manufactured by Polymer Technologies Inc., a New Jersey company. Reticulated foam is typically utilized in filtration. The pore selected is $24-45 \mathrm{psi}$, which provides ample space for biomass accumulation. The tensile strength of the foam ranges between 16-30psi. The foam was obtained in Charcoal Grey, the only available color. The foam's dry weight was recorded. The remaining 10 cultures included no foam and were used for comparison.

\subsubsection{Quantification of Biomass}

Culture growth was measured via chlorophyll levels present in the cultures and total biomass accumulated. Chlorophyll quantifications were carried out every 5 days in order to record algal growth. For this, $5 \mathrm{~mL}$ of each sample was collected and filtered using a Whatman GF/A filter. Chlorophyll extraction and quantification was executed as per section 3.1 .

In order to measure total biomass accumulated, cultures were filtered using a Whatman GF/A filter on the $45^{\text {th }}$ day, in order to trap the biomass. Filter weight was recoded 48 hours after filtering, allowing time for them to dry under a heating lamp. Weight change was recorded and noted as algal biomass. Foam was allowed to dry and weight change was also noted as biomass. 


\subsection{The Impact of Alkaline pH on Algal Growth}

The possibility for reducing culture contamination in open ponds was explored through $\mathrm{pH}$ manipulation. For this experiment, Zarrouk's medium was mixed 1:1 with canal water samples collected for the canal assessment (section 3.1), making the medium half-strength. Zarrouk's medium was selected for its high content of salts and high $\mathrm{pH}$. The only two cultures that demonstrated growth originated from sampling site S308; thus, they were transferred to full strength medium. The medium composition is provided in table 4.

The medium's $\mathrm{pH}$ was adjusted from 8.9 to $9,10,11$, and 12 with a solution of potassium hydroxide, and 3 replicates were set-up per $\mathrm{pH}$ adjustment, for each of the two samples obtained in site $\mathrm{S} 308$. Each replicate contained $70 \mathrm{~mL}$ of medium and $5 \mathrm{~mL}$ of inoculant from the selected cultures, and they were kept in $125 \mathrm{~mL}$ Erlenmeyer flask. The cultures were incubated in a New Brunswick Scientific Excella E24 incubator shaker rotating at $150 \mathrm{rmp}$ for 35 days. Temperature was set at $25^{\circ} \mathrm{C}$, and light was continuous at $380 \mathrm{~lm}$ of intensity (LED bulbs 8.5 -watt, efficacy $45 \mathrm{~lm} /$ watt, $3000 \mathrm{~K}$ warm color temperature, high CRI 84).

Chlorophyll was used as an indicator of culture growth and health, and quantifications were carried out every 7 days. For this, $5 \mathrm{~mL}$ of each sample was collected and filtered using a Whatman GF/A filter. Chlorophyll extraction and quantification was adapted from Dere, et al., (1997) and executed as per section 3.1 


\begin{tabular}{|l|c|c|}
\hline \multicolumn{1}{|c|}{ Component } & \multicolumn{1}{|c|}{$\begin{array}{c}\text { Chemical } \\
\text { Composition }\end{array}$} & $\begin{array}{c}\text { Concentration } \\
\text { (g/L) }\end{array}$ \\
\hline Sodium Bicarbonate & $\mathrm{NaHCO}_{3}$ & 18.00 \\
\hline Sodium Nitrate & $\mathrm{NaNO}_{3}$ & 2.5 \\
\hline Potassium Sulfate & $\mathrm{K}_{2} \mathrm{SO}_{4}$ & 1.00 \\
\hline Sodium Chloride & $\mathrm{NaCl}_{2}$ & 1.00 \\
\hline Potassium Phosphate Dibasic & $\mathrm{K}_{2} \mathrm{HPO}_{4}$ & 0.5 \\
\hline $\begin{array}{l}\text { Magnesium Sulfate } \\
\text { Heptahydrate }\end{array}$ & $\mathrm{MgSO}_{4} \cdot 7 \mathrm{H}_{2} \mathrm{O}$ & 0.2 \\
\hline Na2EDTA & $\mathrm{C}_{10} \mathrm{H}_{14} \mathrm{~N}_{2} \mathrm{Na}_{2} \mathrm{O}_{8}$ & 0.08 \\
\hline Calcium Chloride & $\mathrm{CaCl}_{2}$ & 0.04 \\
\hline Iron (II) Sulfate Heptahydrate & $\mathrm{FeSO}_{4} \cdot 7 \mathrm{H}_{2} \mathrm{O}$ & 0.01 \\
\hline Trace Element Solution & - & $1 \mathrm{~mL}$ \\
\hline \multicolumn{1}{|c|}{ Trace Element Solution } \\
\hline Boric Acid & $\mathrm{H} 3 \mathrm{BO} 3$ & 2.86 \\
\hline $\begin{array}{l}\text { Manganese Chloride } \\
\text { Tetrahydrate }\end{array}$ & $\mathrm{MnCl} \cdot 4 \mathrm{H} 2 \mathrm{O}$ & 1.80 \\
\hline Zinc Sulfate Heptahydrate & $\mathrm{ZnSO} \cdot 7 \mathrm{H} 2 \mathrm{O}$ & 0.22 \\
\hline Copper (II) Sulfate & $\mathrm{Cu} 2 \mathrm{SO} 4$ & 0.08 \\
\hline $\begin{array}{l}\text { Ammonium Molybdate } \\
\text { Tetrahydrate }\end{array}$ & $\begin{array}{c}\text { NH4)6Mo7O24 } \\
4 H 2 O\end{array}$ & 0.02 \\
\hline
\end{tabular}

Table 5. Recipe for Zarrouk's Medium

\subsection{Statistical Analysis}

All statistical analysis was conducted using SPSS 21 (SPSS, Chicago, IL, USA). The different hypothesis are listed per experiment below:

\subsubsection{Canal Water Suitability for Algae Growth}

A one-way ANOVA between subjects was conducted to determine which sampling site displayed a higher level of chlorophyll at the $\mathrm{p}<0.05$ level

\subsubsection{Assessment of Different Growth Media}

A Kruskal-Wallis test was conducted to determine if there is a significant difference in the biomass accumulation among each site as the data was nonparametric. 
Independently, the same test was conducted in order to determine if there is a significant difference in the biomass accumulation in each medium.

\subsubsection{Biomass Production in a Raceway Pond System and Semi-Submerged, Immobilized Cell System}

A two-way ANOVA was conducted to determine if there is a significant difference in the biomass accumulated between the two different types of systems and the nutrient treatment at the $\mathrm{p}<0.05$ level. In addition, a two-way ANOVA was used to determine if there was a significant difference when comparing the biomass accumulated between the mesocosms that received nutrient treatment versus those that did not.

\subsubsection{The Use of Reticulated Foam for Algal Biomass Production}

An independent-sample t-test was conducted to compare the total chlorophyll present in day 45 of the experiment. An independent-samples t-test was conducted to compare the total biomass accumulated in the cultures where the foam was added and the cultures without the foam as well. 


\section{RESULTS}

\subsection{Biomass in Canal Water}

Biomass was found in all the canals sampled at a relatively similar level, except for sampling sites LOX and L-8. Site LOX showed to have the highest level of chlorophyll among the canals sampled. Contrary, site L-8 displayed the lowest amount of chlorophyll. A one-way ANOVA between subjects revealed that there was a significant difference in the level of chlorophyll among the sampling sites at the $\mathrm{p}<0.05$ level $[\mathrm{F}(13,28)=18.71, \mathrm{p}=0.00]$. Furthermore, a post-hoc comparison using the Tukey HSD test indicated that site LOX was significantly different from any other canal and it demonstrated the highest chlorophyll content $(\mathrm{M}=4.37, \mathrm{SD}=0.95)$.

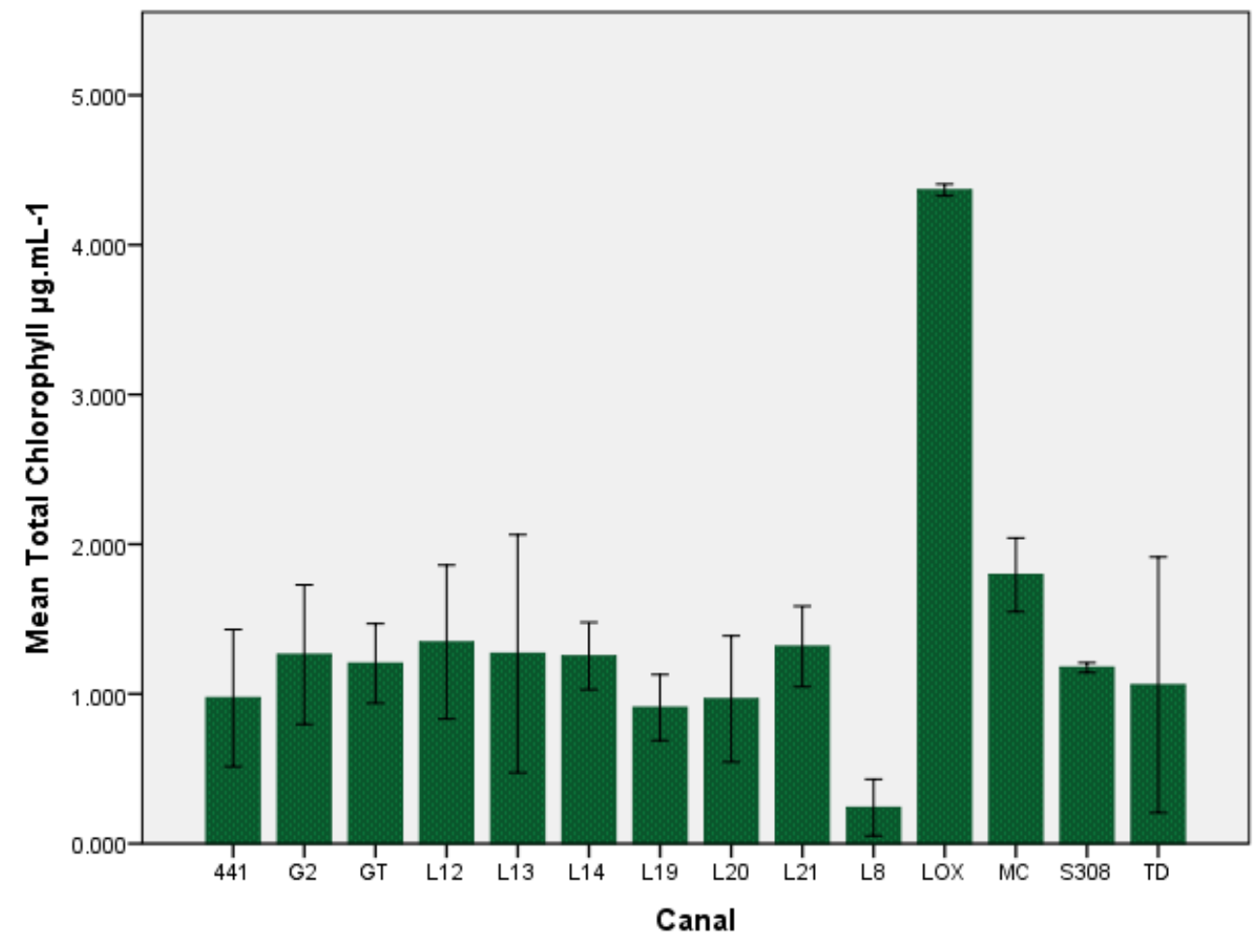

Error Bars: +/- 2 SE

Figure 9. Chlorophyll (in $\mu \mathrm{g} \cdot \mathrm{mL}^{-1}$ ) concentrations found in the EAA canals sampled in July 2013. Site LOX was found to be significantly higher than the rest of the canals sampled. 
Considering the significant difference in chlorophyll, site LOX was selected as a water source for subsequent experiments.

\subsection{Biomass in Canal Water Supplemented with Nutrients}

\subsubsection{Total Chlorophyll}

A comparison in the levels of chlorophyll shows that none of the media used displayed higher levels of chlorophyll in all 3 sites. WC medium displayed the highest levels of chlorophyll in sites S308 and MC; however, it displayed the lowest levels of chlorophyll in LOX cultures. Furthermore, Chu medium displayed the largest amount of chlorophyll in site LOX, and the second largest in sites MC and S308. While DyIII medium displayed the second largest levels of chlorophyll in site LOX, it displayed the lowest in site S308 and MC. The results of the Krusskal-Wallis test revealed that there is no significant difference in chlorophyll $\left(\mu \mathrm{g} \cdot \mathrm{mL}^{-1}\right)$ among the different kinds of media $\left[\mathrm{X}^{2}(2, \mathrm{~N}=27)=1.91 ; \mathrm{p}=0.39\right]$. In addition, the same test revealed that there is no significant difference in the chlorophyll $\left(\mu \mathrm{g} \cdot \mathrm{mL}^{-1}\right)$ present among the different sites $\left[\mathrm{X}^{2}\right.$ $(2, \mathrm{~N}=27)=2.77 ; \mathrm{p}=0.25]$. 


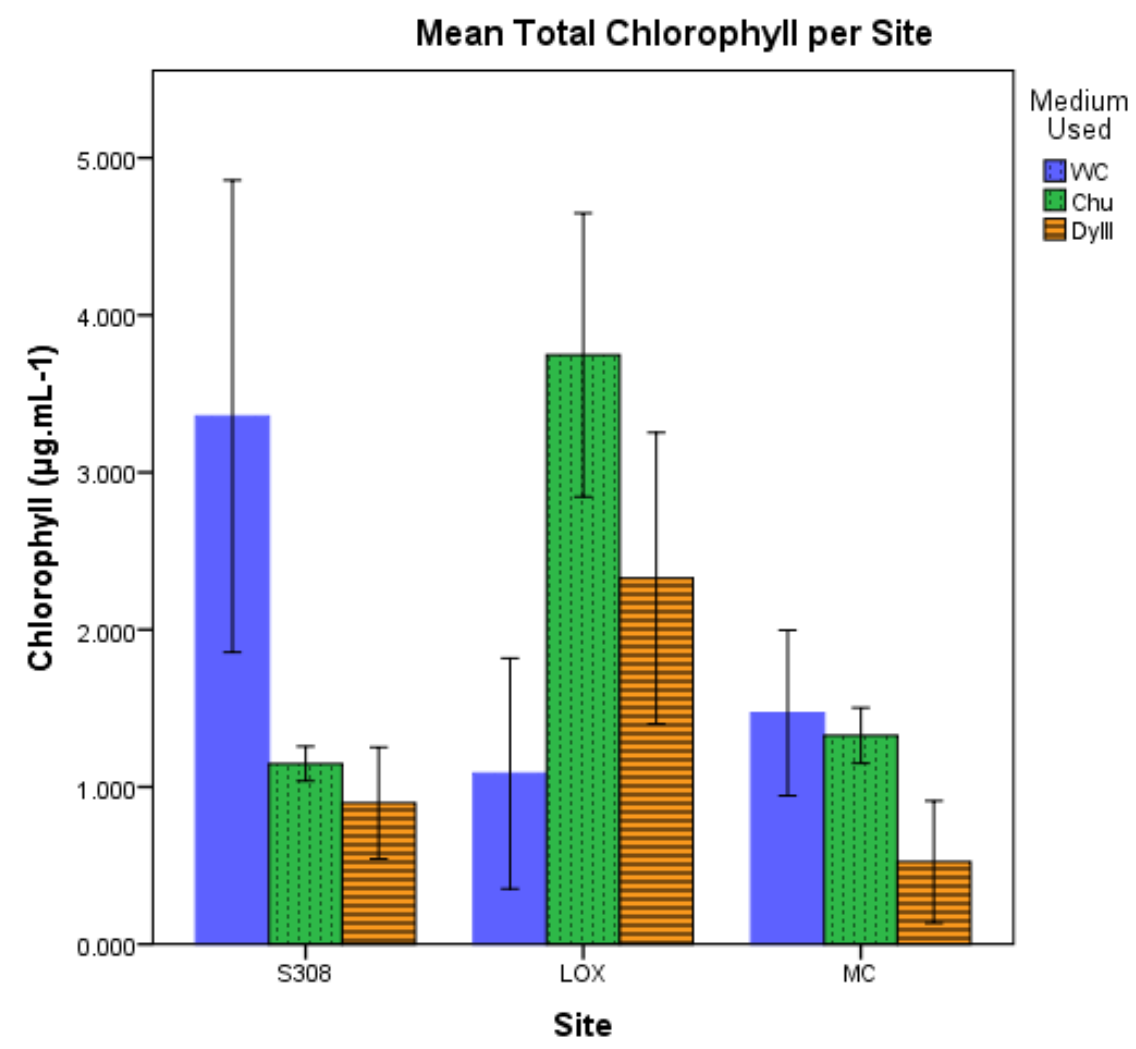

Error Bars: +/- $1 \mathrm{SE}$

Figure 10. Mean Total Chlorophyll (in $\mu \mathrm{g} \cdot \mathrm{mL}^{-1}$ ) Comparison among Sampling Sites per Media. No significant difference was found among media $\left[\mathrm{X}^{2}(2, \mathrm{~N}=27)=1.91 ; \mathrm{p}=0.39\right]$ or among sites $\left[\mathrm{X}^{2}(2\right.$, $\mathrm{N}=27)=2.77 ; \mathrm{p}=0.25]$.

\subsubsection{Dry Weight}

A comparison in the total dry weight revealed that none of the media used accumulated the largest amount of biomass in all 3 sites. WC medium displayed the highest biomass weight in site MC, and the second highest in sites LOX and S308 Furthermore, Chu medium displayed the largest amount of chlorophyll in site LOX and the second largest in site MC; however, it displayed the lowest weight of sampling site S308. Contrary, DyIII medium displayed the largest amount of biomass in site 308. DyIII medium had the second largest biomass weight in site LOX, and it displayed the lowest 
in site MC. The results of the Krusskal-Wallis test revealed that no significant difference in the quantity of biomass accumulated was found among the different kinds of media $\left[\mathrm{X}^{2}(2, \mathrm{~N}=27)=0.23 ; \mathrm{p}=0.9\right]$. In addition, the same test revealed that there is no significant difference in the biomass accumulation among the different sites $\left[\mathrm{X}^{2}(2\right.$, $\mathrm{N}=27)=2.39 ; \mathrm{p}=0.1]$.

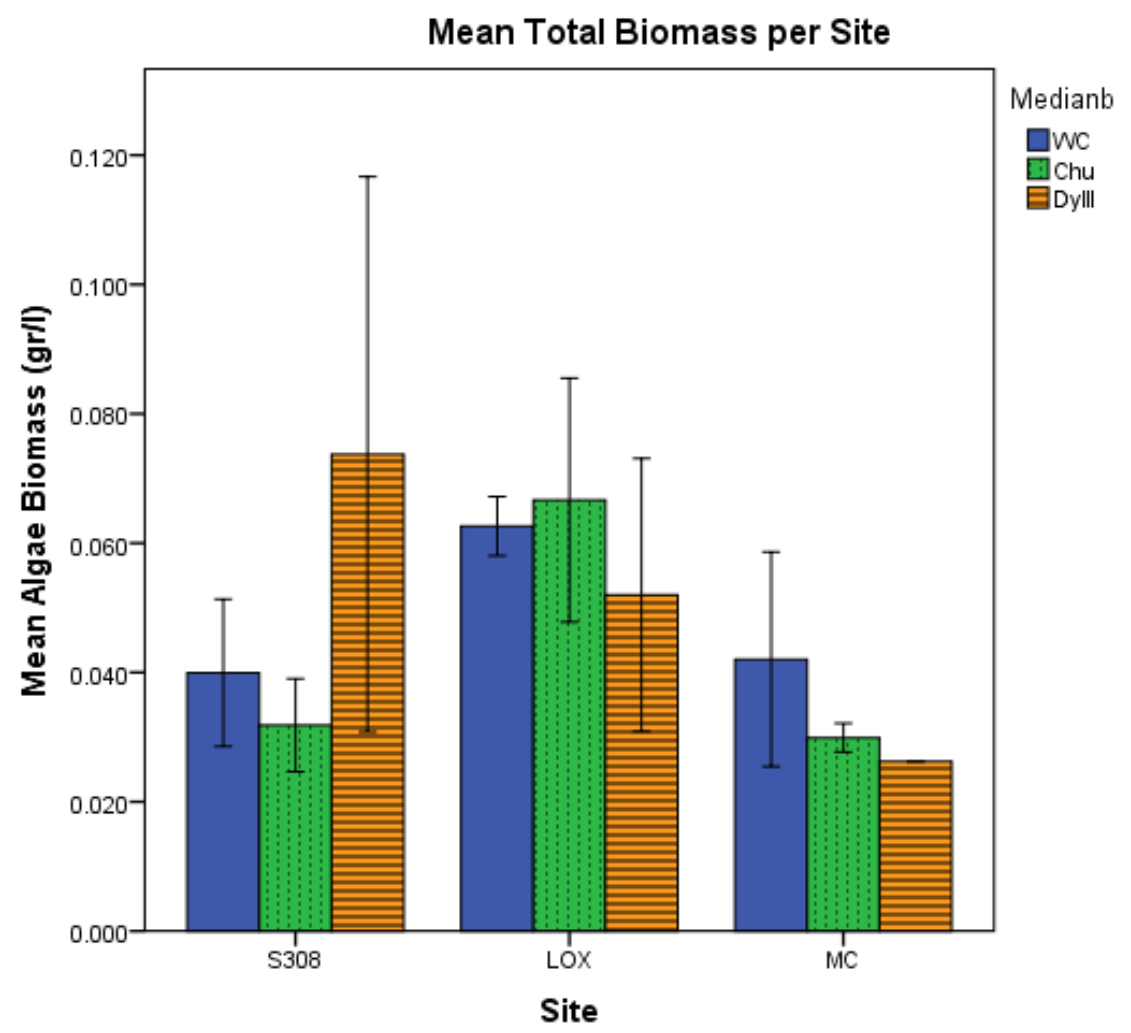

Error Bars: +/- 1 SE

Figure 11. Mean Total Biomass Dry Weight (gr/l) Comparison among Sampling Sites. No significant difference was found among the three different media $\left[\mathrm{X}^{2}(2, \mathrm{~N}=27)=0.23 ; \mathrm{p}=0.9\right]$ or among the three sites $\left[\mathrm{X}^{2}(2, \mathrm{~N}=27)=2.39 ; \mathrm{p}=0.1\right]$.

It is important to note that while no significant difference was found, Chu medium displayed the largest mean of both chlorophyll levels and dry weight in sampling site 
LOX; thus, it was selected as the medium for nutrient amendment in subsequent experiments.

\subsection{Biomass Production in Raceway Pond System}

Biomass accumulated in the raceways pond systems was separated based on nutrient treatment. The bins that received the Chu medium amendment displayed the largest amount of biomass accumulated. An independent-samples t-test confirms there is a significant difference in dry weight between the bins that received the nutrient treatment $(\mathrm{M}=3.77, \mathrm{SD}=1.41)$ and those that did not receive a nutrient treatment $(\mathrm{M}=0.89, \mathrm{SD}=0.50), \mathrm{t}(8)=2.21 ; \mathrm{p}=0.00$

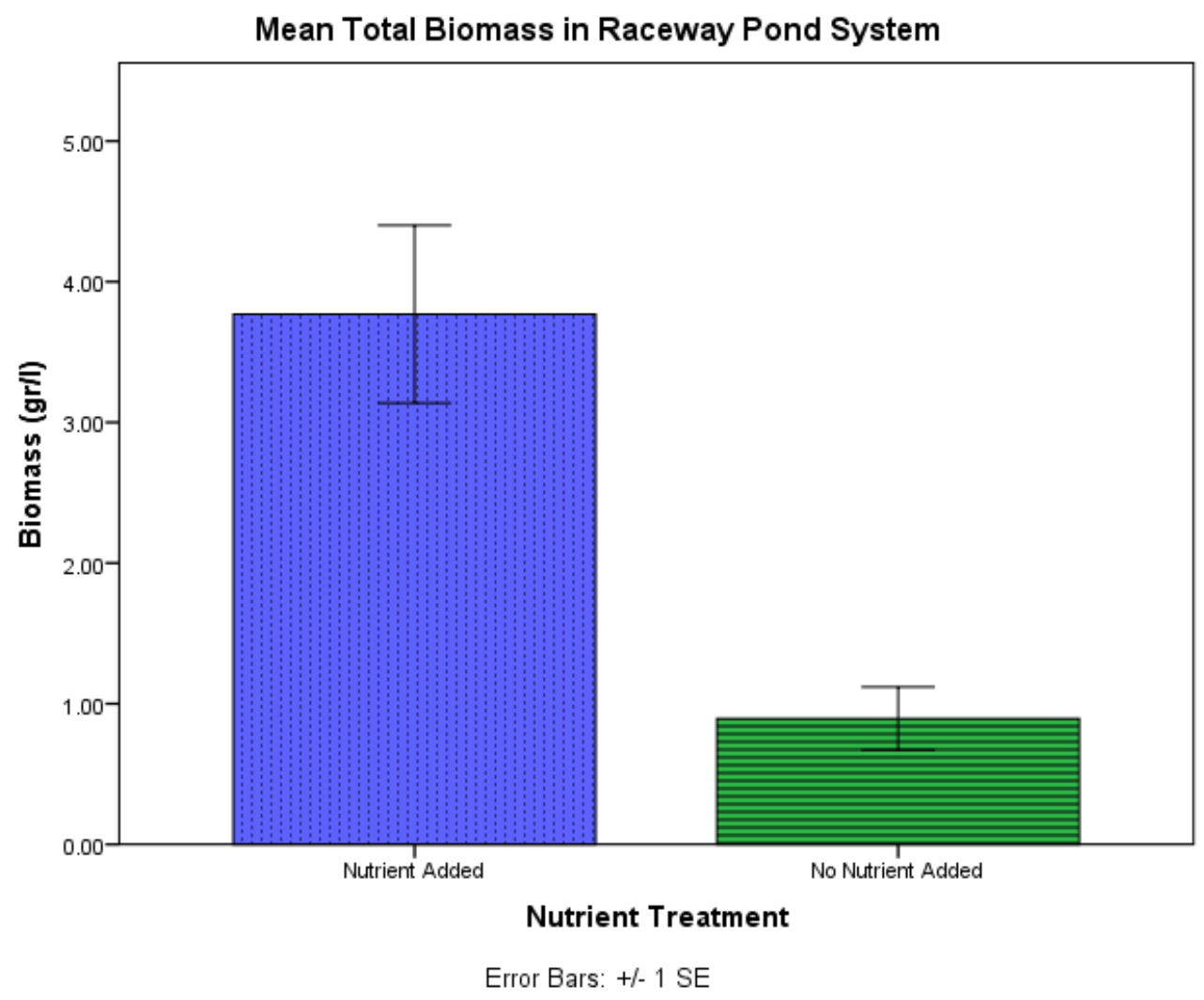


Figure 12. Mean Total Biomass (gr/l) in Raceway Pond Systems. Significant difference was found between the bins that received the nutrient treatment $(\mathrm{M}=3.77, \mathrm{SD}=1.41)$ and those that $\operatorname{did} \operatorname{not}(\mathrm{M}=0.89$, $\mathrm{SD}=0.50), \mathrm{t}(8)=2.21 ; \mathrm{p}=0.00$.

\subsection{Biomass Production in Semi-Submerged, Immobilized Cell System}

Biomass accumulated in the Semi-submerged, Immobilized Cell Systems was divvied based on whether or not a nutrient treatment was added. The bins that received the Chu medium amendment displayed the largest amount of biomass dry weight, about 4 times larger than the bins that did not receive treatment. The results of an independentsamples t-test revealed there is a significant difference in dry weight between the bins that received the nutrient treatment $(\mathrm{M}=3.97, \mathrm{SD}=0.78)$ and those that did not receive a nutrient treatment $(\mathrm{M}=0.79, \mathrm{SD}=0.58), \mathrm{t}(8)=0.99, \mathrm{p}=0.00$.

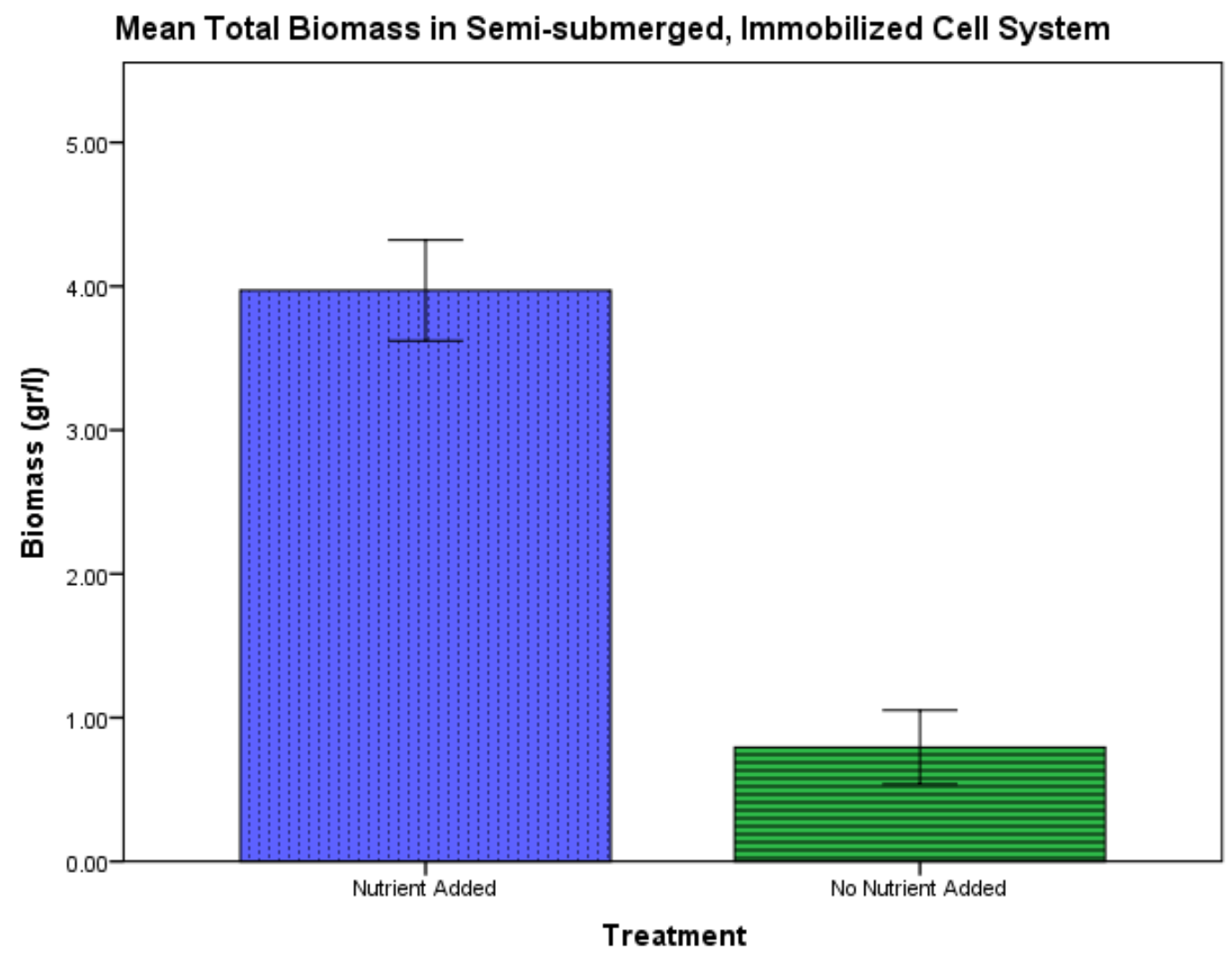

Error Bars: +/- 1 SE 
Figure 13. Mean Total Biomass (gr/l) in Semi-Submerged, Immobilized Cell Systems. Significant difference was found between the bins that received the nutrient treatment $(\mathrm{M}=3.98, \mathrm{SD}=0.78)$ and those that $\operatorname{did} \operatorname{not}(\mathrm{M}=0.79, \mathrm{SD}=0.58), \mathrm{t}(8)=0.99, \mathrm{p}=0.00$.

\subsection{System Comparison}

Both systems displayed similar means of biomass accumulated in the bins with the nutrient amendment and the bins without nutrient treatment. A two-way ANOVA revelead that no significant difference was found in the biomass accumulated between the two tested systems $[F(1,19)=0.16, p=0.90] .$. However, a significant difference was found when comparing the biomass accumulated between the mesocosms that received nutrient treatment versus those that $\operatorname{did} \operatorname{not}[\mathrm{F}(1,19)=57.33, \mathrm{p}=0.00]$. Higher biomass accumulation was observed in the bins that received the nutrient treatment. 


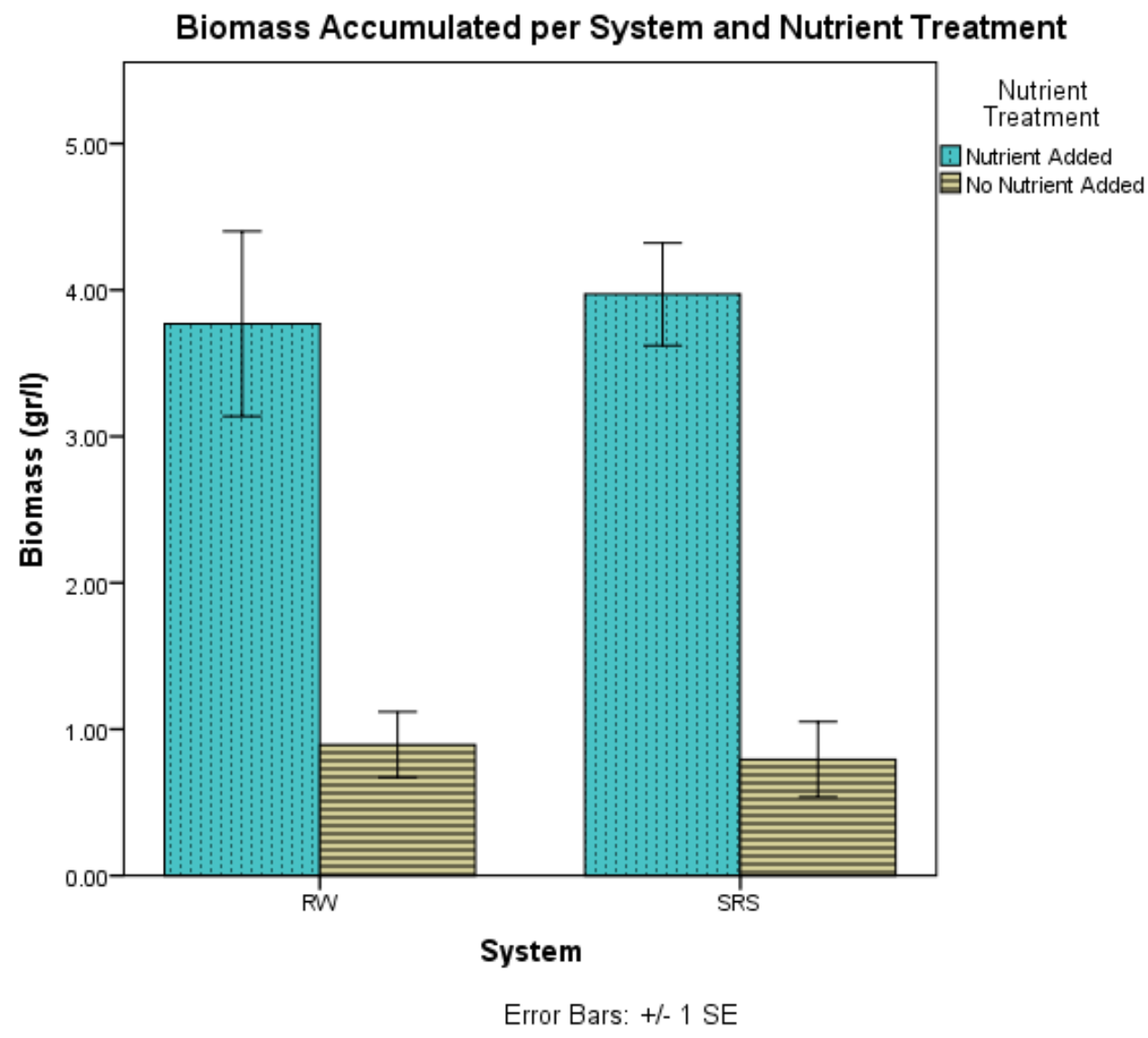

Figure 14. Mean total biomass (gr/l) accumulated in two tested systems; raceway ponds and suspended rotary systems and nutrient treatment

It is important to mention that there was a distinct difference in the biomass accumulated from the mesocosms with nutrient treatment and those without. The bins that received nutrient generated biomass that appeared to be mostly composed of green algae species. Contrary, the bins that did not receive treatment appear to have yielded mostly cyanobacteria and brown algae. 


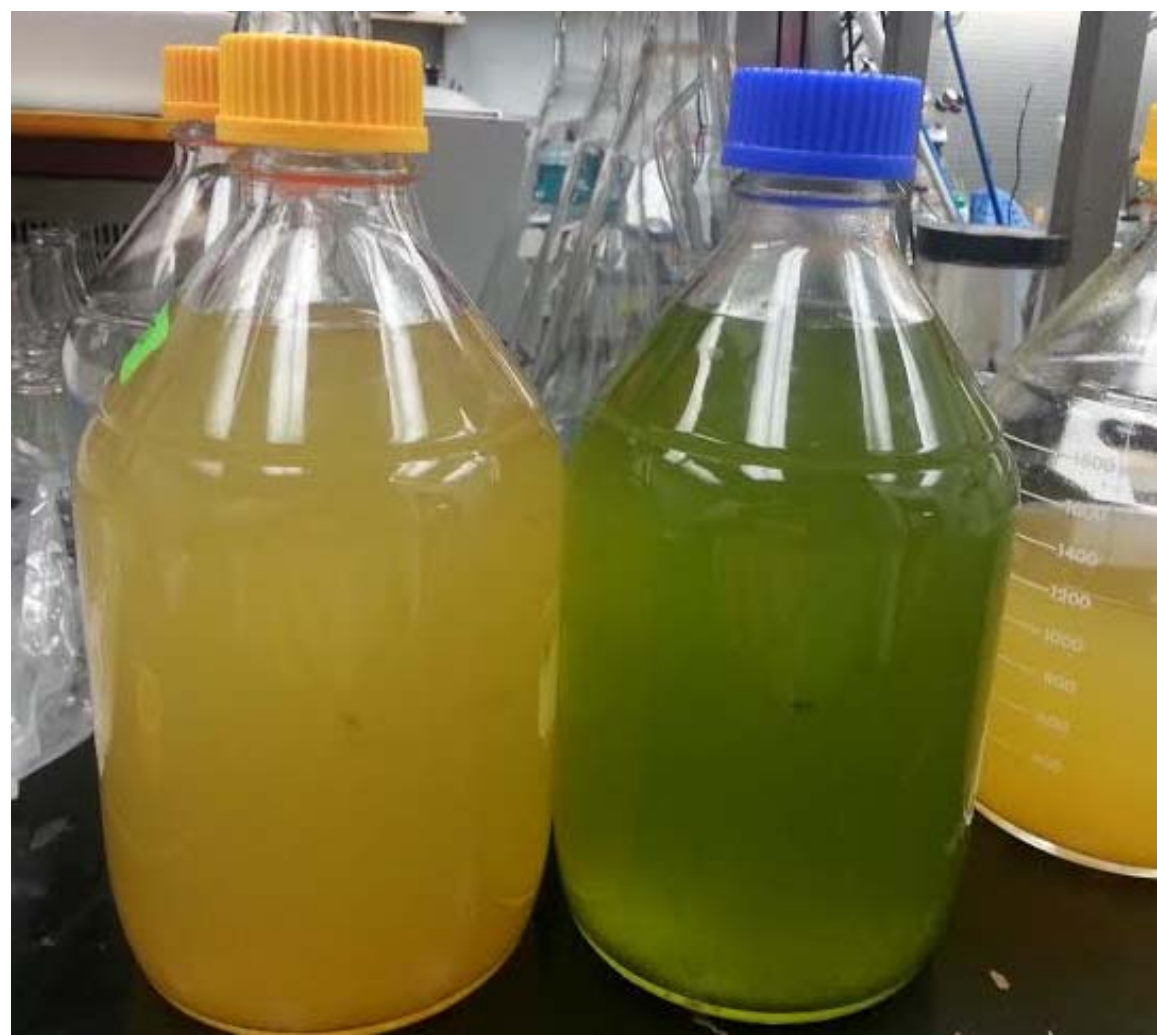

Figure 15. Water collected from the mesocosms. Difference in color can be observed between the bins that received nutrient treatment (right) and those that did not (left).

\subsection{The Use of Reticulated Foam for Algal Biomass Production}

\subsubsection{Chlorophyll}

Results from the chlorophyll quantification demonstrate that algal growth was not constant and population fluctuated throughout the study time. Although the chlorophyll recorded varied, a downwards trend in population size can be seen in Figure 16. It is important to note that cultures that included the foam displayed the largest levels of chlorophyll except for on day 20 of the experiment 


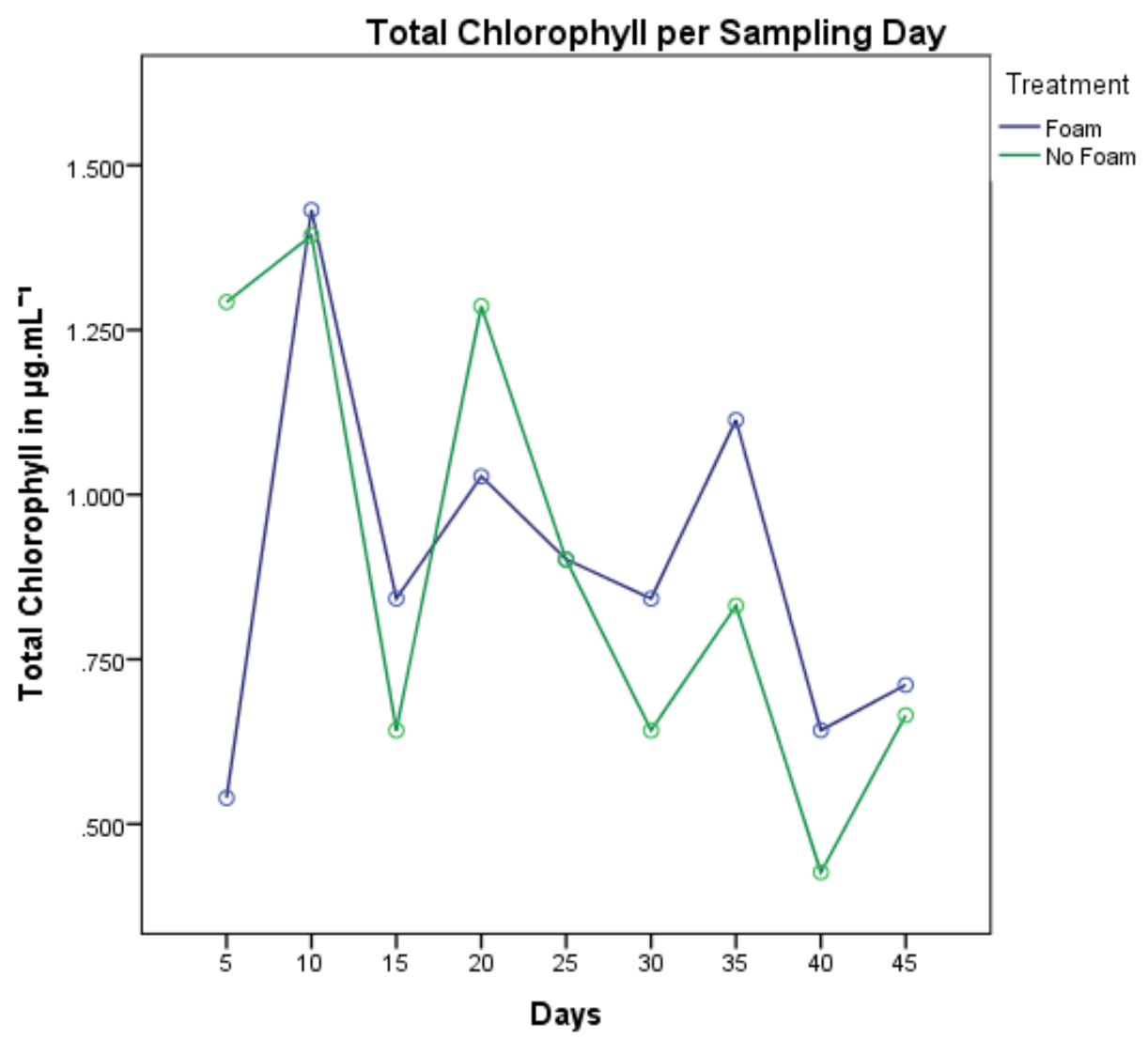

Figure 16. Total mean chlorophyll (ug. $\mathrm{mL}^{-1}$ ) of cultures with and without the foam over the experiment time (45 days).

Samples with the foam displayed higher chlorophyll levels than that those without the foam in day 45. However, chlorophyll levels were considerately lower (half) than the samples with the foam on day 10 , when both treatments displayed their largest levels of chlorophyll. No significant difference was found in the chlorophyll levels in the last day of the experiment (day 45) between the cultures with the foam $(\mathrm{M}=0.71, \mathrm{SD}=0.28)$ and without the foam $(\mathrm{M}=0.66, \mathrm{SD}=0.20)$, although the cultures with the foam displayed a higher mean, $\mathrm{t}(18)=1.48, \mathrm{p}>0.05$. 


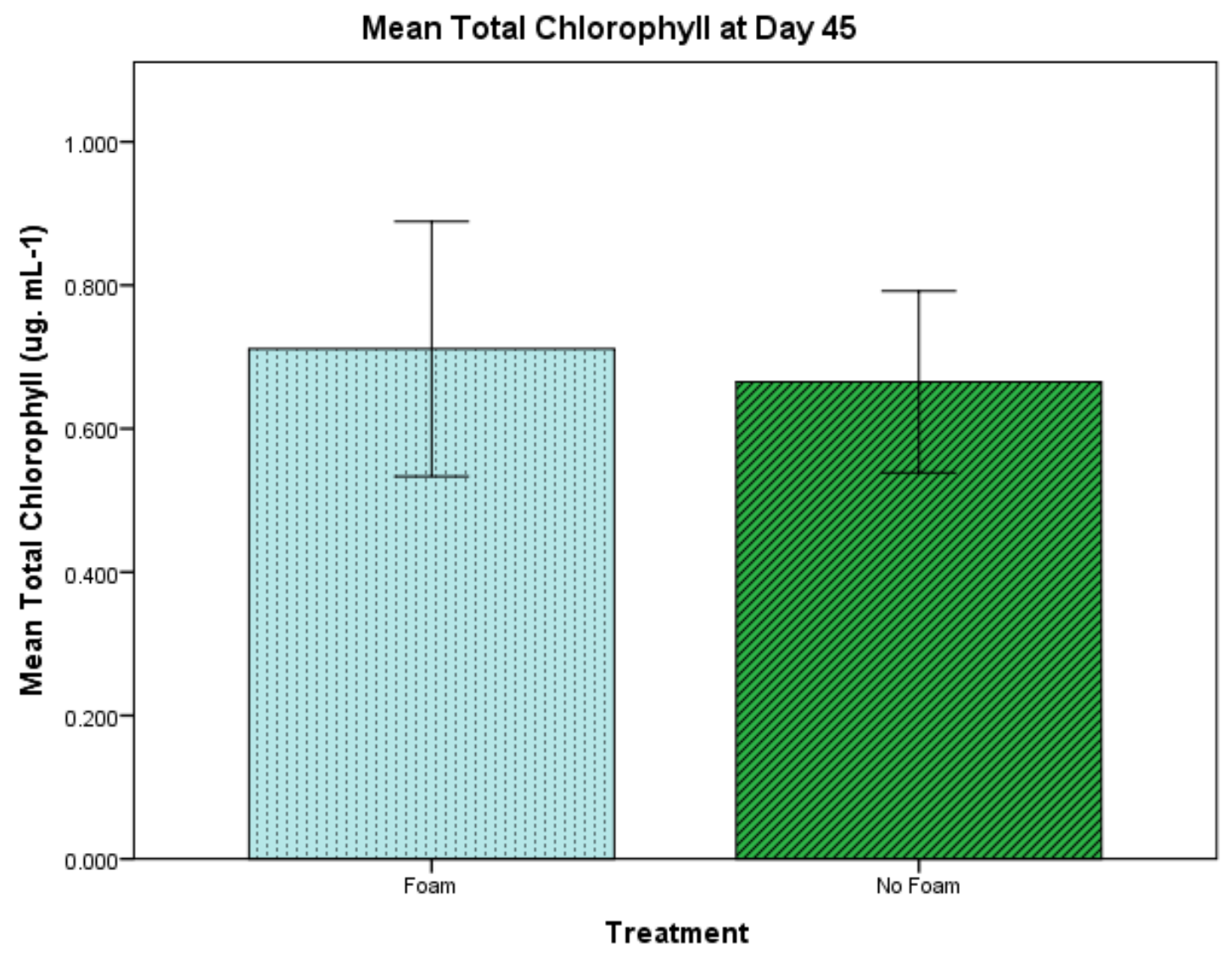

Error Bars: +/- 2 SE

Figure 17. Difference in Chlorophyll levels (ug. $\mathrm{mL}^{-1}$ ) between the cultures where the foam was added and cultures where the foam was not added. No significant difference was found $t(18)=1.48, p>0.05$.

\subsubsection{Dry Weight}

Samples with the foam displayed the highest amount of biomass when observing the dry weight. An independent-samples t-test revealed that there was a significant difference between the biomass accumulated for cultures with the foam $(\mathrm{M}=0.12, \mathrm{SD}=$ $0.003)$ and without the foam $(M=0.09, S D=0.003)$. These results suggest that the use of the foam promotes biomass accumulation, $\mathrm{t}(18)=2.6, \mathrm{p}=0.018$. 
Mean Total Dry Weight of Samples With and Without the Foam

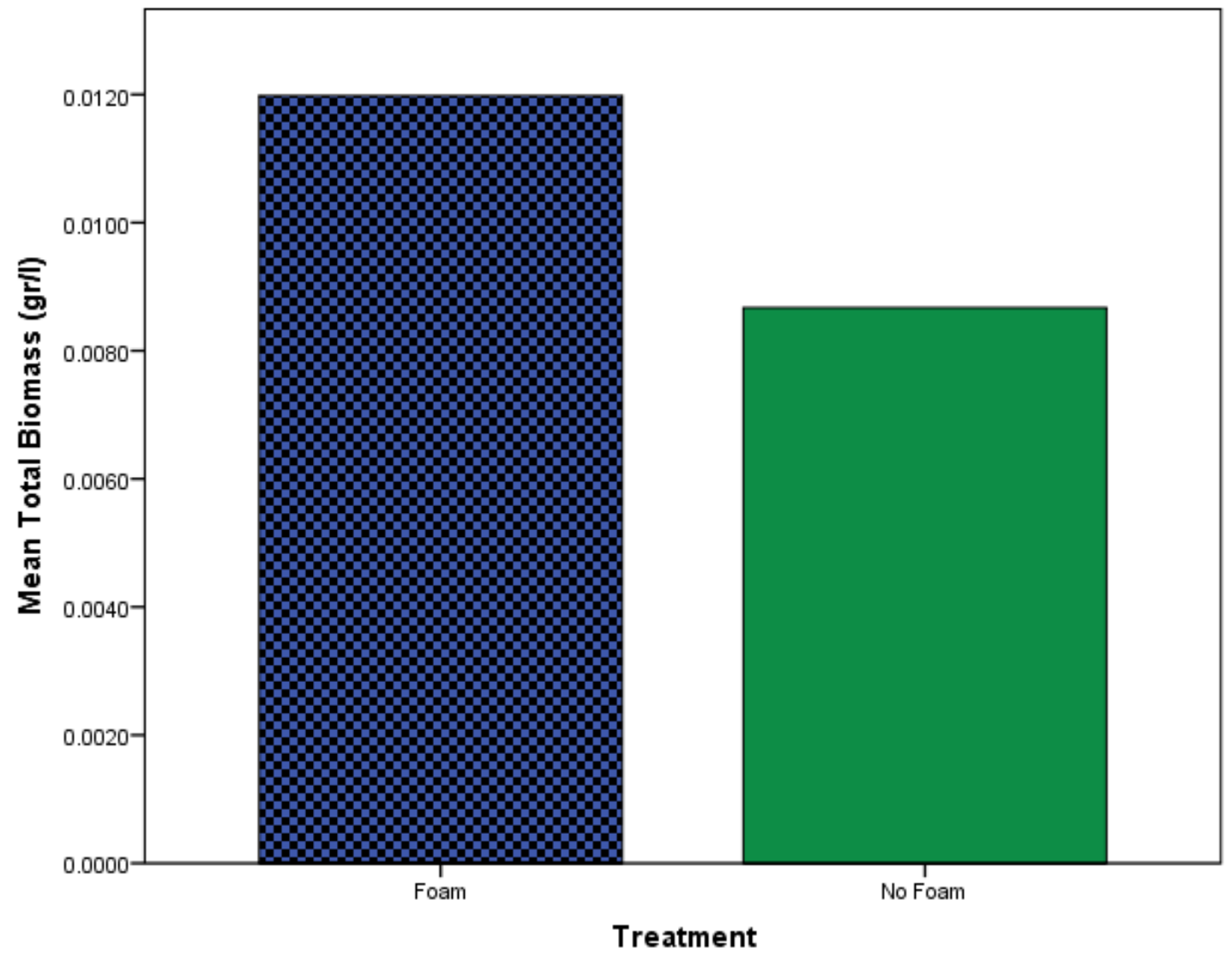

Figure 18. Mean Total Biomass (gr/l) Accumulated in Samples With and Without Reticulated Foam. Samples including the foam displayed a significantly higher amount of biomass $t(18)=2.6, p=0.018$.

\subsection{The Effect of Alkaline pH on Algal Growth}

Cultures grown in Zarrouk's medium displayed growth in alkaline conditions.

While $\mathrm{pH}$ 5-7 is known to be the optimal range for growth of eukaryotic algae (Andersen, 2005), the cultures obtained from site S308's water samples demonstrated to be alkaline tolerant and growth was seen in $\mathrm{pH} 9$ and 10. Cultures exposed to $\mathrm{pH} 11$ and 12 did not survive. Figure 19 displays the chlorophyll measurements recorded for this experiment. 


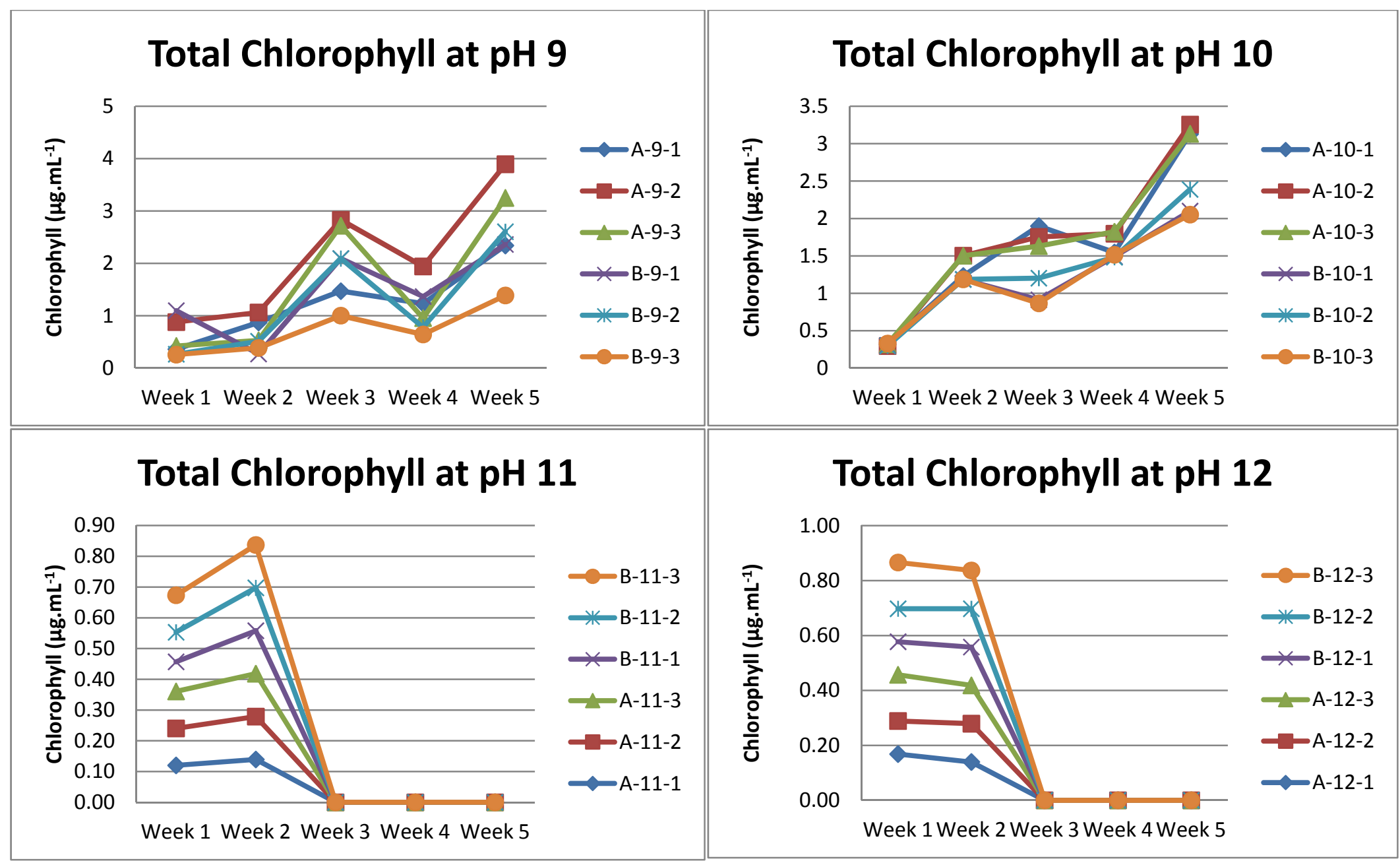

Figure 19. Mean Total Chlorophyll (ug. $\mathrm{mL}^{-1}$ ) Displayed in Cultures Grown in Zarrouk's Medium over 35 Days. 
Furthermore, when comparing the sample from the initial enrichments versus the culture growing in Zarrouk's medium in a microscope, there is a visible decrease in contaminants and in species composition in the algae consortia.

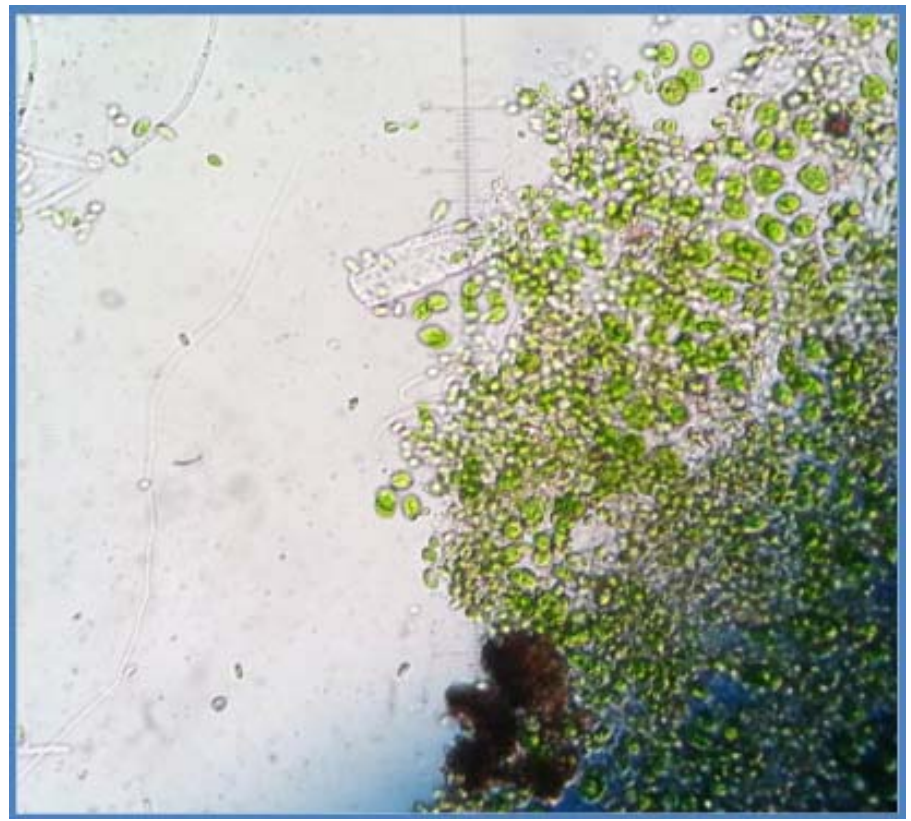

Figure 20. Algae Consortia Present in Cultures from Site S308 Growing in Zarrouk's Medium at Unmodified $\mathrm{pH}(8.9)$.

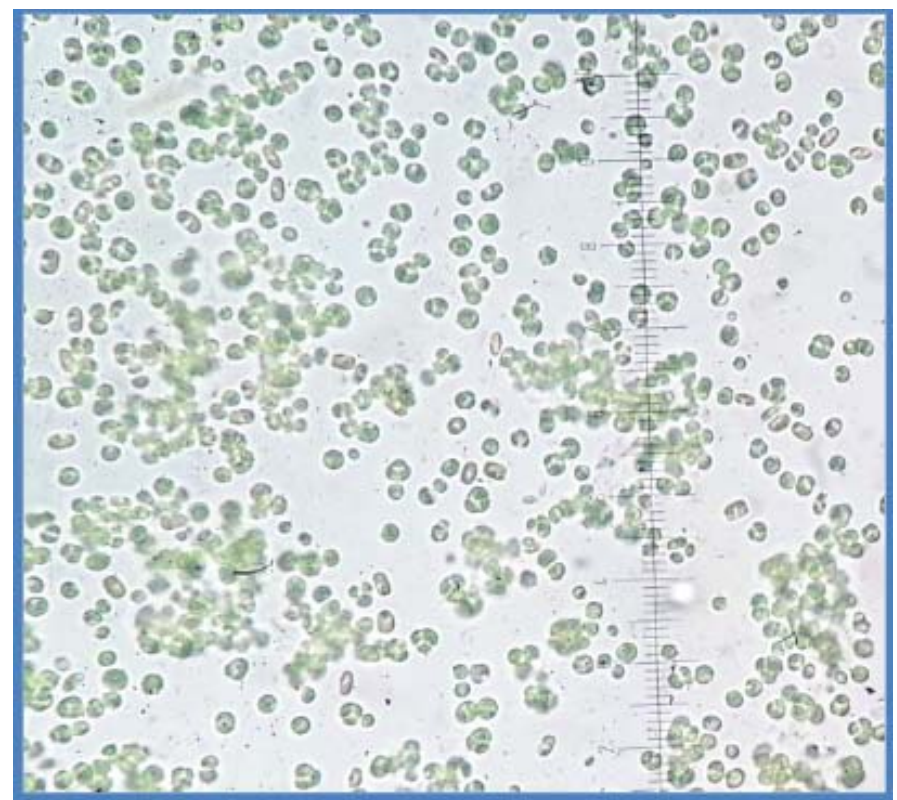

Figure 21. Algae Present in Cultures from Site S308 Growing in Zarrouk's Medium at pH 10 at 35 Days. 


\section{DISCUSSION}

\subsection{Assessment of Canal Water Suitability for Algae Growth}

With 14 major canals and dozens of small ones, there is ample opportunity to collect water from the EAA. Here, water from Lake Okeechobee is transported through large farming fields where it serves for irrigation; then, nutrient-enriched agricultural drainage water is discharged to WCAs, ENP, or the South Florida coastal estuaries. The Everglades Forever Act, passed in 1994, mandates the use of Best Management Practices (BMP) in agricultural fields in order to reduce the nutrient runoff that can have considerable effects on the Everglades, an oligotrophic system. For the EAA, BMP implementation guidelines have been outlined in a South Florida Water Management District (SFWMD) regulatory rule, Chapter 40E-63, Florida Administrative Code (FAC) (Daroub, et. al, 2011). The implementation of BMP is considered a success in the EAA as phosphorous loads have been consistently reduced by $50 \%$ of the historic baseline since their enactment (Daroub, et al., 2011). Because of this successful application, eutrophication was not expected in the EAA canals. However, the presence of herbicides and pesticides may interfere with algal growth and contribute to variation in biomass accumulation among the canals.

The chlorophyll survey in canals revealed that there was a similar amount of biomass on the most of the fourteen canals sampled. These results indicate that collection of algal biomass can be proposed for most of the farms in the EAA. However, the significant difference in sample site LOX demonstrated that this particular canal could potentially outperform all others. In addition, site LOX is adjacent to the Arthur R. 
Marshall Loxahatchee National Wildlife Refuge, an area that could benefit from further nutrient mitigation (Chen, et al., 2012).

It is important to note that the chlorophyll survey was completed during the South Florida rainy season. The total rainfall recorded for July 2013 was 9.65 inches in the east and 9.37 inches in the western portion of the EAA (http://www.sfwmd.gov/portal/page /potal/xweb\%20weather/rainfall\%20historical\%20\%28monthly\%29), which is higher than the average of 6.40 and 7.59in for east and west respectively (http:// www. sfwmd.g ov/portal/page/portal/xweb\%20weather/rainfall\%20historical\%20\%28monthly\%29). The excess water containing nutrients, pesticides, and herbicides is drained from farms to adjacent canals; however, it is believed that present organisms, excess nutrient, and other pollutants may be diluted in higher water levels.

Prior to recommending the EAA as a water source for mass production of algae, it is important to survey the canals during the dry season. In addition, canals surveys can be separated by their proximity to organic or conventional farms, sugarcane or vegetable crop seasons, and by herbicide application. These factors will have significant influence on the algal biomass in the canals as under each scenario the runoff composition will be different. Furthermore, nitrogen and phosphorous content data collected by the SFWMD can be incorporated into the survey in order to have a better understanding of the potential for use of EAA drainage water in biofuel feedstock production.

\subsection{Media Comparison}

While the augmentation of algal biomass using run-off water from farmlands may be considered as a part of BMP in the future, in order to produce sufficient biomass using 
EAA water under the present conditions, nutrient enrichment will be necessary. There are many different kinds of isolation media that target specific green microalgae species (Andersen, 2011). For this project, three media were chosen for their generalized use, simplicity in preparation, availability of ingredients, and resemblance to lake water composition. Site LOX was selected as a baseline. Two additional sites, S308 and MC were recommended by SFWMD's staff because of their accessibility and history of spikes in chlorophyll levels.

The comparison of these sites yielded no significant difference neither in the accumulation of biomass nor in the levels chlorophyll present in the water. However, they demonstrate that algal biomass augmentation can be completed in different areas of the EAA with nutrient enrichment; thus, supporting the idea that establishing of raceway ponds in farms can become a constant source of feedstock for biofuels. In addition, these systems could be included to the list of BMP in the area. Moreover, having a reliable source of feedstock could have a positive impact in the production and use of regional biofuels in the state of Florida.

On the other hand, while it was hoped that a specific medium composition would favor more biomass accumulation, the experimental results, however, provided little support for this theory; therefore, no specific nutrient combination can be recommended for the implementation of these systems. Nonetheless, the use of herbicides and pesticides, and cross contamination are source of concern for the possibility of biomass augmentation on a larger scale.

Future research should aim at exploring the biomass yielded when using the fertilizer currently applied in different areas of the EAA. This would give farmers a better 
understanding of how much biomass they could generate and sell for profit without any additional materials and costs to the farm. Larger farms would be especially benefited from a nutrient studies as they can be carried out in the small canal and ditches that divide the property into smaller fragments, which would also demonstrate the efficacy of employing algae as a BMP for the property.

For subsequent experiments, medium Chu was selected, and all of its components were added to canal water obtained from site LOX.

\subsection{Biomass Production in a Raceway Pond System and Semi-submerged, Immobilized Cell System}

In order to determine if biomass augmentation is possible on a larger scale, mesocosms were built. These represent the two types of systems that can be recommended for use in the EAA. The first one is a small-scale mimic raceway pond that can potentially be suggested to farmers in order to trap runoff in their property while generating income from algal biomass. These structures are inexpensive and easy to build and operate. On the other hand, a semi-submerged rotary system could potentially be used if a surface is provided for algae to attach. The material that is going to be used in the semi-submerged rotary system for algal surface attachment must be durable, inexpensive, and allow for easy harvesting of the biomass. Unlike the raceway ponds, these semi-submerged structures could be installed in major and minor canals and levees and they could be owned and operated by the SFWMD, or the county government. Involvement of governmental agencies in the generation of feedstock is likely to signal restored confidence in the biofuel industry producers, and promote private sector participation in South Florida 
Polytech ${ }^{\circledR}$ reticulated foam was chosen for trapping algal biomass in the semisubmerged system. The foam is typically used for filtration and claims to retain small particulates. The use of the foam was tested in both laboratory condition and outdoors. In both cases, water from sampling site LOX was used as a base for preparing growth medium, into which components from Chu medium were added.

The mesocosms were compared on their nutrient treatment. A significant difference was found in biomass accumulation between the two treatments. The results support the hypothesis that additional nutrient input will promote algal growth and biomass accumulation in EAA water. Nonetheless, because a smaller amount of biomass was gathered from the mesocosms where nutrients were not added, the implementation of a biomass collecting systems can be recommended for the small canals that separate larger farms, where nutrient levels are expected to be higher as a result of nutrient runoff. Here, algal biomass augmentation system can also act as a tool for nutrient reduction.

It is important to mention that the distinction of the resulting biomass between the systems that received nutrient treatments and the systems that did not. Green algae appear visibly dominant in the bins where nutrients were added. Contrary, the biomass accumulated from bins where no nutrients were added consisted predominantly of cyanobacteria. These results were expected as cyanobacteria has known dominance in low-nutrient, fresh water settings (Jensen, et al., 1994; Olding, et al., 2000; Rattan, et al., 2012). In addition, similar to the results obtained by Ernst, et al. (2005), the biomass obtained from the mesocosms with no nutrient treatment appears to be phycoerythrin rich. Because it falls out if the scope of this research, identification of species was not sought. 
In addition, a comparison of total algal biomass generated revealed that there is no significant difference between the two systems. This does not support the hypothesis that increased surface area for algae attachement will promote higher growth rates and biomass accumulation. The foam's dark color might have caused it to absorb and retain more heat, thus making the environment less conducive for algae. Nonetheless, these can be encouraging results. Because there is no significant difference between the systems, recommendation can be given to farmers depending on land availability and accessibility to canals in the farms without compromising the amount of biomass production. In addition, mass production of algal biomass can be recommended even for farms that do not possess separating ditches or canals by building raceway ponds.

Finally, the water used for this experiment was collected on July, 2014. Similar to July, 2013, the rainy season in 2014 experienced higher than usual rainfall. Therefore, it is possible that the nutrient concentration in the canals was lower because of dilution. Future research should aim for comparing the two biomass augmentation systems during the dry season, when nutrient levels in run-off and canal water are expected to increase. In addition, vegetables are grown in the EAA during the dry season, and this change in crops may affect the combination of nutrients in the water and the concentration of pesticides and herbicides present.

\subsection{The Use of Reticulated Foam for Algal Biomass Production}

While the results of this experiment are not sufficient evidence to determine that temperature of the foam prevented the accumulation of biomass while outdoors, it opens the opportunity for additional research. First, it is important that the semi-submerged, 
rotary system be tested during the dry season when average ambient temperature is lower than the one during the raining season. Next, in order to determine if this system can be recommended to farmers in the EAA, studies using scale-up models should be explored. In addition, the possibility of adding the foam to a raceway pond paddle wheel (combining the two systems) should be considered. Finally, the use of the reticulated foam in a photobioreactor should be considered. The latter option is ideal for farms where space is limited and start-up costs are not a determining factor. The use of photobioreactors may also be appealing to private ventures who are solely dedicate to the mass production of algal biomass for biofuel manufacturing.

One of the key findings from the experiment was the observation that the reticulated foam captured $67 \%$ of the biomass collected from the cultures in which the foam was submerged ( $0.08 \mathrm{gr}$ out of $0.12 \mathrm{gr})$. Thus, adding the foam to an enclosed system may improve the efficiency in biomass harvesting and dewatering, a major hurdle in mass production of algae (Uduman, et al., 2010). This sheds a positive light on the use of foams in photobiareactors, as it will allow for biomass harvesting without the use of sophisticated equipment. Nonetheless, because of their simplicity and inexpensive costs, it is recommended to explore the use of the foam in open systems; therefore, future research should focus on how to improve the rotary system. While many details can be improved, using a lighter colored foam may be a simple way to determine if their efficacy can be improved.

\subsection{The Impact of Alkaline pH on Algae Growth}

The mix of Zarrouk's medium with canal water yielded only 3 cultures that displayed growth: S308, TD, and MC. These surviving samples were inoculated in full- 
strength medium, and only the cultures from site S308 survived and displayed growth. This was not surprising as samples from site S308 were obtained from a Lake Okeechobee outflow. "The Lake" as it is popularly referred to, has a basic $\mathrm{pH}$ that ranges from 7.75-8.5 (James, et al., 1995). Therefore, it is believed that organisms present in the sample will not only be able to handle the alkalinity, but thrive in it.

While all cultures seemed to be flourish with the initial $\mathrm{pH}$ adjustment, those subjected to $\mathrm{pH} 11$ and 12 died. Nonetheless, cultures in $\mathrm{pH} 9$ and 10 experienced higher growth than even those grown in canal water. Moreover, periodic observations revealed that the cultures appeared less diverse and fewer bacteria and fungi were observed. It was then concluded that high alkaline conditions may help limit contaminants and competing organisms.

These results are encouraging, especially when considering species-specific cultivations. This is particularly the case for high lipid producing species used for the production of biodiesel. While it may not be the case for other freshwater bodies, algae in samples obtained from the Lake Okeechobee outflow appear to be tolerant to alkaline conditions which could have important implications for the regional development of the biofuels industry.

Biomass was not collected for this part of the project as additional experiments need to be completed in the future. Selection for native algal strains with alkalihalotolerance capability will be more desirable; this makes it possible for growing algae in brackish waste water and reducing fresh water use. If the algae are grown in photobioreactors, algal alkali-halotolerance is of advantage as $\mathrm{pH}$ and salinity of the algal culture usually increases due to sodium carbonate accumulation when carbon dioxide is 
supplied as carbon source. In addition with algal strains that are alkali-halotolerant, it is also possible to recycle carbon dioxide in a more cost-efficient way using biocarbonate system (Chi et al., 2011). Finally, it would be interesting to see if the alkalinity of the medium would deter algae predators. 


\section{CONCLUSION}

Benefiting from Florida's optimal sunlight and mild temperature, the EAA can serve as a location for the mass production of algae for biofuels. The purpose of this thesis was to explore the potential use of water from the EAA in the production of algal biomass for biofuel production. A survey of fourteen canals revealed that algal biomass is present in the area. Specifically, a canal adjacent to the Arthur R. Marshall Loxahatchee National Wildlife Refuge, named LOX in this research, displayed the largest amount of biomass in the EAA, promoting itself as the preferred source for water. Moreover, in spite of farm nutrient runoff, it was determined that nutrient treatments are necessary for mass production of algae using canal water. A media experiment using revealed that similar quantities of biomass can be obtained from different areas of the EAA; thus, strengthening the idea that feedstock production is possible.

However, a comparison of the systems tested in this research yielded no significant difference in the amount of biomass harvested. These results provide flexibility in the recommendations as other factors such as surplus of land or canal availability can be considered without compromising for lower biomass yields when choosing a system. As the hypothesis stating the rotary, semi-submerged system would yield more biomass was not supported, laboratory test on the reticulated foam were performed. In this case the foam aided in the production of biomass.

Finally, it was determined that species present in the EAA are tolerant to alkaline conditions. Although identification of the species is pending, it is believed that utilizing them for outdoor mass production under alkaline conditions can lead to successful harvesting of algal biomass for fermentation. 


\section{RECOMMENDATIONS}

While continued research on algae biofuels is ongoing, it has certainly already proven to be superior choice as a replacement of liquid fuels derived from petroleum. Nonetheless, algal-fuel technology is very complex and it is continuously evolving as opportunities for improvement arise; therefore, investment in research and development in technical expertise is still needed to make algal fuels a marketable and profitable product. In order to more effectively reap the benefits of algae fuels, it is important to consider to the advantages of regional productions, especially in Florida, where optimal growing conditions for algae exists.

Taking in consideration the results obtained in this research, further studies are recommended in the EAA. In particular, a continued and comprehensive canal survey will determine specific locations where mass production of algal biomass is possible. In addition, cross-contamination reduction can be further explored by selective enrichment process for both salt tolerance (halotolerance) and alkaline-tolerant without impacting the biomass production capability. Next, species identification through rDNA sequence analysis is required. Finally, outdoor trials are recommended in order to determine the culture medium efficacy to reduce cross-contamination and increase biomass production. 


\section{References}

Andersen, R. A. (Ed.). (2005). Algal culturing techniques. Academic press.

Becker, E. W. (1994). Microalgae: biotechnology and microbiology (Vol. 10). Cambridge University Press.

Berndes, G. (2002). Bioenergy and water-the implications of large-scale bioenergy production for water use and supply. Global environmental change, 12(4), 253271.

Berrios, M., Martín, M. A., Chica, A. F., \& Martín, A. (2010). Study of esterification and transesterification in biodiesel production from used frying oils in a closed system. Chemical Engineering Journal, 160(2), 473-479.

Black, G., Curran, H. J., Pichon, S., Simmie, J. M., \& Zhukov, V. (2010). Bio-butanol: Combustion properties and detailed chemical kinetic model. Combustion and Flame, 157(2), 363-373.

Borowitzka, M.A. (1997) Microalgae for aquaculture: opportunities and constraints. Journal of Applied Phycology 9:393-401.

Borowitzka, M. A., \& Moheimani, N. R. (2012). Algae for biofuels and energy (Vol. 5). Springer.

Chang, H., (2007). Marine Biodiversity and Systematics. Research Programmes Retrieved from http://www.niwa.cri.nz/rc/prog/marinebiodiversity/obj7.

Chapman, V. J. (2013). An introduction to the study of algae. Cambridge University Press.

Chen, C., Meselhe, E., \& Waldon, M. (2012). Assessment of mineral concentration impacts from pumped stormwater on an Everglades Wetland, Florida, USAUsing a spatially-explicit model. Journal of Hydrology, 452, 25-39.

Chi, Z., O'Fallon, J. V., \& Chen, S. (2011). Bicarbonate produced from carbon capture for algae culture. Trends in biotechnology, 29(11), 537-541.

Chimney, M. J., \& Goforth, G. (2001). Environmental impacts to the Everglades ecosystem: a historical perspective and restoration strategies. Water Science \& Technology, 44(11), 93-100.

Christi, Y., "Biodiesel from Microalgae,” Biotechnology Advances, Vol. 25, 2007, pp. 294-306. 
Cooper, R. M. (1989). AN ATLAS OF TH E EVERGLADES AGRICULTURAL AREA SURFACE WATER MANAGEMENT BASINS.

Christenson, L., \& Sims, R. (2011). Production and harvesting of microalgae for wastewater treatment, biofuels, and bioproducts. Biotechnology advances, 29(6), 686-702.

Daroub, S. H., Van Horn, S., Lang, T. A., \& Diaz, O. A. (2011). Best management practices and long-term water quality trends in the Everglades Agricultural Area. Critical Reviews in Environmental Science and Technology, 41(S1), 608-632.

Demirbas, A., \& Fatih Demirbas, M. (2011). Importance of algae oil as a source of biodiesel. Energy Conversion and Management, 52(1), 163-170.

Dere, S., Günes, T., \& Sivaci, R. (1998). Spectrophotometric determination of chlorophyll-A, B and total carotenoid contents of some algae species using different solvents. Turkish Journal of Botany, 22, 13-17.

Dürre, P. (2007). Biobutanol: an attractive biofuel. Biotechnology journal, 2(12), 1525 1534.

Ellis, J. T., Hengge, N. N., Sims, R. C., \& Miller, C. D. (2012). Acetone, butanol, and ethanol production from wastewater algae. Bioresource technology, 111, 491-495.

Elobeid, A., \& Hart, C. (2007). Ethanol expansion in the food versus fuel debate: how will developing countries fare?. Journal of Agricultural \& Food Industrial Organization, 5(2).

Enger, E. D., \& Smith, B. F. (2002). Environmental Science: a study of interrelationships. Eight Edition.

Ernst, A., Deicher, M., Herman, P. M., \& Wollenzien, U. I. (2005). Nitrate and phosphate affect cultivability of cyanobacteria from environments with low nutrient levels. Applied and environmental microbiology, 71(6), 3379-3383.

Gleick, P. H. (2008). The World's Water 2008-2009: the biennial report on freshwater resources. Island Press.

Goldman, J. C. (1979). Outdoor algal mass cultures-II. Photosynthetic yield limitations. Water Research, 13(2), 119-136.

Halim, R., Gladman, B., Danquah, M. K., \& Webley, P. A. (2011). Oil extraction from microalgae for biodiesel production. Bioresource technology, 102(1), 178-185. 
Harvey, B. G., \& Meylemans, H. A. (2011). The role of butanol in the development of sustainable fuel technologies. Journal of Chemical Technology and Biotechnology, 86(1), 2-9.

Hochman, G., Kaplan, S., Rejagopal, D. and Zilberman, D. (2012). Biofuel and FoodCommodity Prices. Agriculture (2) 272-281

Hossain, A. S., Salleh, A., Boyce, A. N., Chowdhury, P., \& Naqiuddin, M. (2008). Biodiesel fuel production from algae as renewable energy. American journal of biochemistry and biotechnology, 4(3), 250-254.

Izuno, F. T., \& Bottcher, A. B. (1992). Implementation and Verification of BMPs for Reducing $P$ Loading in the EAA. Institute of Food and Agricultural Sciences, University of Florida.

James, R. T., Smith, V. H., \& Jones, B. L. (1995). Historical trends in the Lake Okeechobee ecosystem. 3. Water quality. Archiv für Hydrobiologie, Supplement, 107(1), 49-69.

Jang, Y. S., Malaviya, A., Cho, C., Lee, J., \& Lee, S. Y. (2012). Butanol production from renewable biomass by clostridia. Bioresource technology, 123, 653-663.

Jensen, J. P., Jeppesen, E., Olrik, K., \& Kristensen, P. (1994). Impact of nutrients and physical factors on the shift from cyanobacterial to chlorophyte dominance in shallow Danish lakes. Canadian Journal of Fisheries and Aquatic Sciences, 51(8), 1692-1699.

Jensen, J. R., Halvorsen, K. E., \& Shonnard, D. R. (2011). Ethanol from lignocellulosics, US federal energy and agricultural policy, and the diffusion of innovation. Biomass and Bioenergy, 35(4), 1440-1453.

Khanal, N. (1982). Consumptive Use and Supplemental Water Requirements of Crops Grown in the Everglades Agricultural Area. Resource Planning Department. South Florida Water Management District.

Kennedy, D. (ed) (2006). Science magazine's state of the planet 2006-2007. Washington D.C.: Island Press.

Kumar, M., \& Gayen, K. (2011). Developments in biobutanol production: new insights. Applied Energy, 88(6), 1999-2012.

Lang, X., Dalai, A. K., Bakhshi, N. N., Reaney, M. J., \& Hertz, P. B. (2001). Preparation and characterization of bio-diesels from various bio-oils. Bioresource technology, 80(1), 53-62. 
Maryking, (2007). "Will algae beat its competitors to become the king source of biofuels?" Environmental Graffiti. http://www.environmentalgraffiti.com/?p=237.

Meher, L. C., Vidya Sagar, D., \& Naik, S. N. (2006). Technical aspects of biodiesel production by transesterification - a review. Renewable and sustainable energy reviews, 10(3), 248-268.

McHugh, D. J. (2003). A guide to the seaweed industry-FAO Fisheries Technical Paper 441. Food and Agriculture Organization of the United Nations, Rome.

Milder, J. C., McNeely, J. A., Shames, S. A., \& Scherr, S. J. (2008). Biofuels and ecoagriculture: can bioenergy production enhance landscape-scale ecosystem conservation and rural livelihoods?. International Journal of Agricultural Sustainability, 6(2), 105-121.

National Research Council. Sustainable Development of Algal Biofuels in the United States. Washington, DC: The National Academies Press, 2012.

Narendar, P. (2010). Screening and Identification of Everglades Algal Isolates for Biodiesel production.

Olding, D. D., Hellebust, J. A., \& Douglas, M. S. (2000). Phytoplankton community composition in relation to water quality and water-body morphometry in urban lakes, reservoirs, and ponds. Canadian Journal of Fisheries and Aquatic Sciences, 57(10), 2163-2174.

Oswald, W. J., \& Gotaas, H. B. (1957). Photosynthesis in sewage treatment. Trans. Am. Soc. Civ. Eng, 122, 73-105.

Parmar, A., Singh, N. K., Pandey, A., Gnansounou, E., \& Madamwar, D. (2011). Cyanobacteria and microalgae: a positive prospect for biofuels. Bioresource technology, 102(22), 10163-10172.

Rattan, K. J., Taylor, W. D., \& Smith, R. E. (2012). Nutrient status of phytoplankton across a trophic gradient in Lake Erie: evidence from new fluorescence methods. Canadian Journal of Fisheries and Aquatic Sciences, 69(1), 94-111.

Rijsberman, F. R. (2006). Water scarcity: fact or fiction?. Agricultural water management, 80(1), 5-22.

Round, F. E. (1984). The ecology of algae. CUP Archive.

Rogers, L. J., \& Gallon, J. R. (1988). Biochemistry of the Algae and Cyanobacteria. 
Sander, K., \& Murthy, G. S. (2010). Life cycle analysis of algae biodiesel. The International Journal of Life Cycle Assessment, 15(7), 704-714.

Schiel-Bengelsdorf, B., Montoya, J., Linder, S., \& Dürre, P. (2013). Butanol fermentation. Environmental technology, 34(13-14), 1691-1710.

Schnepf, R. (2010). AgricultureBased Biofuels: Overview and Emerging Issues. DIANE Publishing.

Scott, S. A., Davey, M. P., Dennis, J. S., Horst, I., Howe, C. J., Lea-Smith, D. J., \& Smith, A. G. (2010). Biodiesel from algae: challenges and prospects. Current Opinion in Biotechnology, 21(3), 277-286.

Shapovalov, O. I., \& Ashkinazi, L. A. (2008). Biobutanol: Biofuel of second generation. Russian Journal of Applied Chemistry, 81(12), 2232-2236.

Singh, A., Nigam, P. S., \& Murphy, J. D. (2011). Mechanism and challenges in commercialisation of algal biofuels. Bioresource technology, 102(1), 26-34.

Soeder, C. J. (1980). Massive cultivation of microalgae: results and prospects. Hydrobiologia, 72(1-2), 197-209.

Stevenson, R. J., Bothwell, M. L., Lowe, R. L., \& Thorp, J. H. (1996). Algal ecology: Freshwater benthic ecosystem. Academic press.

Sun, Y., \& Cheng, J. (2002). Hydrolysis of lignocellulosic materials for ethanol production: a review. Bioresource technology, 83(1), 1-11.

Tsukahara, K., \& Sawayama, S. (2005). Liquid fuel production using microalgae. Journal of the Japan Petroleum Institute, 48(5), 251.

Tredici, M. R. (2004). Mass production of microalgae: photobioreactors. Handbook of microalgal culture: Biotechnology and applied phycology, 1, 178-214.

Udoma, I., Halfhide, T., Gilliea, B., Dalrymple, O., Zaribaf, B. H., Zhang, Q., \& Ergas, S. J. (2012). Harvesting Microalgae Grown on Wastewater. Proceedings of the Water Environment Federation, 2012(13), 3646-3658.

Uduman, N., Qi, Y., Danquah, M. K., Forde, G. M., \& Hoadley, A. (2010). Dewatering of microalgal cultures: a major bottleneck to algae-based fuels. Journal of Renewable and Sustainable Energy, 2(1), 012701.

United States Energy Information Administration (EIA) (a). Energy Perspectives: Fossil fuels dominate U.S. energy consumption. Washington, DC., 2012. Print. $<\mathrm{http}$ ://www.eia.gov/todayinenergy/detail.cfm?id=9210>. 
United States Environmental Protection Agency (EPA) (2012). Biofuels: Basic information. Retrieved from http://www.epa.gov/ncea/biofuels/basicinfo.htm

Vijayaraghavan, K., \& Hemanathan, K. (2009). Biodiesel production from freshwater algae. Energy \& Fuels, 23(11), 5448-5453.

Waltz, E. (2013). Algal biofuels questioned. Nature biotechnology, 31(1), 12-12.

Wang, L., Li, Y., Chen, P., Min, M., Chen, Y., Zhu, J., \& Ruan, R. R. (2010). Anaerobic digested dairy manure as a nutrient supplement for cultivation of oil-rich green microalgae $<\mathrm{i}>$ Chlorella $</ \mathrm{i}>$ sp. Bioresource technology, 101(8), 2623-2628.

Wan, M., Liu, P., Xia, J., Rosenberg, J. N., Oyler, G. A., Betenbaugh, M. J., \& Qiu, G. (2011). The effect of mixotrophy on microalgal growth, lipid content, and expression levels of three pathway genes in Chlorella sorokiniana. Applied microbiology and biotechnology, 91(3), 835-844.

Wedel, R. von, \& Point Richmond, C. A. (1999). Marine Biodiesel. National Renewable Research Laboratory.

Wellburn, A. R., \& Lichtenthaler, H. (1984). Formulae and program to determine total carotenoids and chlorophylls a and $\mathrm{b}$ of leaf extracts in different solvents. In Advances in photosynthesis research (pp. 9-12). Springer Netherlands.

World Health Organization (2003). Water Sanitation and Health. Obtained from: http://www.who.int/water_sanitation_health/hygiene/en/.

World Bank (2008). Rising Food Prices: Policy Options and World Bank Response. Washington, DC. April. Obtained from siteresources.worldbank.org/.../risingfoodprices_backgroundnote_apr08.pdf

Yacobucci, Brent D (2007). Fuel Ethanol: Background and Public Policy Issues. Congressional Research Service: 1-27

Yuan, X., Wang, M., Park, C., Sahu, A.K., Ergas, S.J., 2012. Microalgae growth using high strength wastewater followed by anaerobic co-digestion. Water Environ. Res. 84, 396-404. 